\title{
Volatile loss from melt inclusions in pyroclasts of differing sizes
}

\author{
Alexander S. Lloyd · Terry Plank • Philipp Ruprecht • \\ Erik H. Hauri $\cdot$ William Rose
}

Received: 2 April 2012/Accepted: 22 August 2012

(C) Springer-Verlag 2012

\begin{abstract}
We have investigated the loss of $\mathrm{H}_{2} \mathrm{O}$ from olivine-hosted melt inclusions (MIs) by designing an experiment using tephra samples that cooled at different rates owing to their different sizes: ash, lapilli, and bomb samples that were deposited on the same day (10/17/74) of the sub-Plinian eruption of Volcán de Fuego in Guatemala. Ion microprobe, laser ablation-ICPMS, and electron probe analyses show that MIs from ash and lapilli record the highest $\mathrm{H}_{2} \mathrm{O}$ contents, up to $4.4 \mathrm{wt} \%$. On the other hand, MIs from bombs indicate up to $30 \%$ lower $\mathrm{H}_{2} \mathrm{O}$ contents (loss of $\sim 1 \mathrm{wt} \% \mathrm{H}_{2} \mathrm{O}$ ) and $10 \%$ post-entrapment crystallization of olivine. This evidence is consistent with the longer cooling time available for a bomb-sized clast, up to $10 \mathrm{~min}$ for a $3-4-\mathrm{cm}$ radius bomb, assuming conductive cooling and the fastest $\mathrm{H}$ diffusivities measured in olivine
\end{abstract}

Communicated by T. L. Grove.

Electronic supplementary material The online version of this article (doi:10.1007/s00410-012-0800-2) contains supplementary material, which is available to authorized users.

A. S. Lloyd $(\bowtie) \cdot$ T. Plank · P. Ruprecht

Lamont Doherty Earth Observatory, Columbia University,

Columbia, NY, USA

e-mail: alloyd@1deo.columbia.edu

T. Plank

e-mail: tplank@1deo.columbia.edu

P. Ruprecht

e-mail: ruprecht@1deo.columbia.edu

E. H. Hauri

Carnegie Institution of Washington, Washington, DC, USA

e-mail: hauri@ciw.edu

W. Rose

Michigan Tech University, Houghton, MI, USA

e-mail: raman@mtu.edu
(D $\sim 10^{-9}$ to $10^{-10} \mathrm{~m}^{2} / \mathrm{s}$ ). On the other hand, several lines of evidence point to some water loss prior to eruption, during magma ascent and degassing in the conduit. Thus, results point to both slower post-eruptive cooling and slower magma ascent affecting MIs from bombs, leading to $\mathrm{H}_{2} \mathrm{O}$ loss over the timescale of minutes to hours. The important implication of this study is that a significant portion of the published data on $\mathrm{H}_{2} \mathrm{O}$ concentrations in olivine-hosted MIs may reflect unrecognized $\mathrm{H}_{2} \mathrm{O}$ loss via diffusion. This work highlights the importance of reporting clast and MI sizes in order to assess diffusive effects and the potential benefit of using water loss as a chronometer of magma ascent.

Keywords Melt inclusion - Olivine - Water concentration · Diffusive re-equilibration rate $\cdot$ Volatiles $\cdot$ Magma ascent

\section{Introduction}

The concentration of $\mathrm{H}_{2} \mathrm{O}$ in magmas has been an elusive but critical parameter to the understanding of several fundamental processes, including subduction zone recycling (Sisson and Layne 1993; Cervantes and Wallace 2003; Portnyagin et al. 2007), mantle melting (Hirth and Kohlstedt 1996; Kelley et al. 2010), magma differentiation (Grove et al. 2002; Zimmer et al. 2010), and magma ascent and eruption (Cashman 2004). Because the solubility of water in silicate melts decreases substantially at low pressures, $\mathrm{H}_{2} \mathrm{O}$-rich magmas will degas upon ascent, erupting with a minute fraction of their original dissolved concentration. Melt inclusions (MIs), which are trapped within phenocrysts during crystallization, are exceptions to the degassing process. Isolated from the degassing magma, and quenched to glass upon eruption, a MI may retain pre- 
eruptive volatile concentrations. In situ analyses of MIs provide the only direct approach to measuring a magma's initial volatile content (Wallace 2005).

MIs can form when a defect in crystal growth allows some of the melt surrounding a crystal to be trapped by subsequent crystallization (Faure and Schiano 2005; Kohout and Nielsen 2004; Kent 2008; Baker et al. 2005). These droplets of melt then become aliquots of the magma, potentially retaining information about volatile concentrations, depth, and temperature at the time of entrapment (Metrich and Wallace 2008). MIs can form at different stages during the evolution of a magmatic body, recording details about changes in composition during fractional crystallization, mixing, assimilation, and ascent (Frezzoti 2001).

The fidelity of the MI record is critical to their interpretation and application (Danyushevsky et al. 2000; Gaetani and Watson 2000; Baker 2008). Although inclusions can be found in any phenocryst phase, olivine is especially useful because of its presence in primitive magmas that have experienced minimal degassing and crustal interaction. On the other hand, it has been increasingly recognized that olivines are by no means perfect containers and that their melt inclusions may experience re-equilibration due especially to the rapid diffusion of water, but also an increasing list of other chemical species (Portnyagin et al. 2008; Spandler and O'Neill 2010). For example, if the magma surrounding the olivine changes composition, a concentration gradient can drive the olivine and MI toward re-equilibration (Roedder 1981). The degree of re-equilibration is controlled by the partition coefficient, the length and timescale, and the rate of diffusion for the specific components of interest (Qin et al. 1992). For the major elements $\mathrm{Fe}^{2+}$ and $\mathrm{Mg}^{2+}$, melt inclusions, which can reside for months to years as part of their host mineral at magmatic temperatures in magma chambers, are capable of homogenizing to a state of equilibrium with their host minerals and the surrounding melt (Danyushevsky et al. 2000; Gaetani and Watson 2002; Cottrell et al. 2002). Although complete major and trace element re-equilibration is rare, concentration gradients and knowledge of the degree of disequilibrium can be used as a chronometer for storage and eruption processes (Costa et al. 2008; Danyushevsky et al. 2002). $\mathrm{H}_{2} \mathrm{O}$, however, may diffuse orders of magnitude faster than the metal cations. Recent laboratory experiments have shown that $\mathrm{H}_{2} \mathrm{O}$ in MIs can re-equilibrate with a surrounding magma through their host olivine on the order of days at $0.5 \mathrm{~mm}$ length scales (Portnyagin et al. 2008; Gaetani et al. 2012; Chen et al. 2011). Other studies find evidence for even faster diffusive loss of water from olivine, on the timescale of hours to minutes (Hauri 2002; Demouchy et al. 2006; Massare et al. 2002). While there is debate over the exact mechanisms and rates of $\mathrm{H}_{2} \mathrm{O}$ loss from olivine, the timescales (days to minutes) are highly relevant to syn- and post-eruptive volcanic phenomena.

In addition to magma mixing (months to days) and ascent (days to minutes), post-eruptive cooling represents a third timescale during which $\mathrm{H}_{2} \mathrm{O}$ can re-equilibrate with degassing magma at surface temperatures and pressures. Posteruptive cooling can be defined as the time period between fragmentation in the volcanic conduit and the subsequent deposition and equilibration with the surface temperature. Previous workers (Hauri 2002; Portnyagin et al. 2007; Wallace et al. 2003; Berlo et al. 2012) have noted that MIs from fast-cooling pyroclastic deposits have higher $\mathrm{H}_{2} \mathrm{O}$ concentrations than those from slowly cooled lava flows. Volcanic bomb interiors and lava flows may remain at magmatic temperatures on the order of minutes to days (Thomas and Sparks 1992; Hon et al. 1994), potentially long enough for diffusive loss of $\mathrm{H}_{2} \mathrm{O}$. Whereas re-equilibration of MIs during their residence in a magma chamber is a distinctively longer timescale, the timescales associated with ascent and post-eruptive cooling can be similar for a subPlinian eruption with a relatively fast ascent rate.

The concern is that some MIs with low water concentrations have been misinterpreted as water-poor pre-eruptive melt, when it is possible that instead they have suffered $\mathrm{H}_{2} \mathrm{O}$ loss during ascent and post-eruptive cooling. For example, the low $\mathrm{H}_{2} \mathrm{O}$ contents $(<0.5 \mathrm{wt} \%)$ in melt inclusions from Galunggung volcano were reported by Sisson and Bronto (1993) as evidence for dry decompression melting beneath some arcs. In another example, Collins et al. (2009) interpreted melt inclusions with lowerthan-expected $\mathrm{H}_{2} \mathrm{O}$ contents as evidence for a sustained interaction between a percolating gas phase and stored magma. These melt inclusions, however, were selected from volcanic bombs (Sisson and Bronto 1993) and lava flows (Collins et al. 2009) and, given the recent experimental work on water loss, may have experienced diffusive $\mathrm{H}_{2} \mathrm{O}$ loss during post-eruptive cooling. Although an increasing concern, diffusive $\mathrm{H}_{2} \mathrm{O}$ loss has yet to be related quantitatively to tephra cooling rates. This is the purpose of the present study.

In order to isolate the effect of post-eruptive cooling rates, we designed a natural experiment that exploits a unique sample suite of tephra of variable clast size collected on a single day of an eruption. Pyroclasts of different sizes will cool at different rates, with ash and lapilli samples cooling rapidly (seconds), and volcanic bombs cooling more slowly (minutes). Selecting samples erupted on the same day minimizes confounding temporal changes in magma composition, especially initial volatile contents. Based on calculated cooling rates and measured $\mathrm{H}_{2} \mathrm{O}$ concentrations, our results quantify the timescales of $\mathrm{H}_{2} \mathrm{O}$ loss from olivine-hosted MIs during post-eruptive cooling. Although the experiment was set up to test the clast cooling hypothesis, we also consider 
how the ascent history may differ between bombs, ash, and lapilli samples. This study should guide future sampling efforts by defining what types of tephra deposits are ideal for MI studies that seek to recover maximum $\mathrm{H}_{2} \mathrm{O}$ concentrations prior to ascent and degassing.

\section{Background}

We targeted samples from the 1974 eruption of Volcán de Fuego, Guatemala, for this study of $\mathrm{H}_{2} \mathrm{O}$ loss in MIs during post-eruptive cooling. Major sub-Plinian eruptions (VEI 4) occurred on 4 days between October 14 and October 23, 1974 , and produced $0.1 \mathrm{~km}^{3}$ of porphyritic, water-rich, high-aluminum basalt (Rose et al. 2008). During each day of this eruption, freshly fallen tephra was mapped and collected at various sites 7-80 km from the vent by William Rose and Samuel Bonis of the Instituto Geográfico Nacional, Guatemala City. Bonis collected and documented more than 350 samples of eruptive material including very fine scoriaceous ash $(<1 \mathrm{~mm})$ and an assortment of bombs and lapilli from $1 \mathrm{~cm}$ to $6 \mathrm{~cm}$. From this group of samples, seven ash, lapilli, and bomb samples were chosen to be analyzed, all of which were erupted on October 17, approximately $8 \mathrm{~km}$ from the summit (Table 1). The October 17-18 event (best described as sub-Plinian; Rose et al. 2008) was the largest of the four main phases of the eruption and produced a column of at least stratospheric height. Intense explosions with 1-min periodicity yielded ash flow and airfall deposits that account for $40 \%$ of the total ash of the eruption (Rose et al. 1978). The composition of the bulk ash over the course of the 1974 eruption remained within a limited, basaltic range (47.0-52.6 wt \% $\mathrm{SiO}_{2}$; Rose et al. 1978; Carr and Walker 1987).

Extensive prior work on the volatile and major element composition of the October 17-18, 1974, Fuego samples provides important constraints on the pre-eruptive concentration of $\mathrm{H}_{2} \mathrm{O}$ in MIs, which was previously found to be high $\left(>4 \mathrm{wt} \% \mathrm{H}_{2} \mathrm{O}\right)$ and provides a useful starting point in this study (Rose et al. 1978; Sisson and Layne 1993; Roggensack 2001a). From the beginning of the eruption on October 14 to the conclusion of intense activity on October 23, the bulk ash shifted toward more mafic compositions (from 4 to $8 \% \mathrm{MgO}$ and $\sim 3.5$ to 12.5 vol\% olivine; Rose et al. 1978). Ash from the October 17 phase contains the highest concentrations of some incompatible elements (e.g., $\mathrm{K}_{2} \mathrm{O}, \mathrm{Ba}, \mathrm{La}, \mathrm{Th}$ ) and the mid-range for compatible elements. The eruption as a whole contained a fairly restricted olivine population, in particular the October 17 phase, with compositions between $\mathrm{Fo}_{72}$ and $\mathrm{Fo}_{78}$ with an average of $\mathrm{Fo}_{73.8} \pm 1.6$ for 39 analyses (Table 2). Previous MI and plagioclase zoning studies have suggested different possible scenarios for the magma plumbing system (Anderson 1984). The 1974 eruption either tapped a vertically stratified magma chamber (Rose et al. 1978), or ascent was preceded by mixing of magmas fractionated at various crustal depths (Roggensack 2001a; Berlo et al. 2012). Although crustal contamination has been implicated for some Guatemala volcanoes, Fuego eruptive products have the highest ${ }^{143} \mathrm{Nd} /{ }^{144} \mathrm{Nd}$ in this sector of the arc (Carr et al. 1990; Heydolph et al. 2012) and so may not be as affected by crustal interactions. The relative uniformity of incompatible trace element ratios in October 17 melt inclusions also points to limited crustal interaction during this phase of the eruption (see below).

\section{Methods}

\section{Sample preparation}

During sample preparation, special care was taken to ensure the separation of the three sizes of pyroclasts in order to assess $\mathrm{H}_{2} \mathrm{O}$ loss as a function of different clast cooling rates (Table 1). Three samples were taken to represent volcanic ash (particles with a diameter $<2 \mathrm{~mm}$ ); two samples represented lapilli (particles with a diameter
Table 1 Samples analyzed from the October 17, 1974, eruption of Volcán de Fuego. The analyzed lapilli clasts were $21,22,25,25$, and $29 \mathrm{~mm}$ (diameter), and the dimensions for the bombs were

$5 \times 5 \times 4 \mathrm{~cm}$ for $134 \mathrm{D}$ and $5 \times 5 \times 3 \mathrm{~cm}$ for $137 \mathrm{~B}$

\begin{tabular}{llllll}
\hline $\begin{array}{l}\text { Sample } \\
\text { name }\end{array}$ & $\begin{array}{l}\text { Reported } \\
\text { analyses }\end{array}$ & $\begin{array}{l}\text { Pyroclast } \\
\text { classification }\end{array}$ & $\begin{array}{l}\text { Location } \\
\text { (Guatemala) }\end{array}$ & $\begin{array}{l}\text { Distance } \\
\text { (km from summit) }\end{array}$ & $\begin{array}{l}\text { Direction } \\
\text { (from summit) }\end{array}$ \\
\hline VF-74-127 & 5 & Ash & Los Pajalcs & 8.5 & $\mathrm{~N}$ \\
VF-74-131 & 3 & Ash & Quisache & 8 & $\mathrm{NW}$ \\
VF-74-132 & 4 & Ash & Ycpocapa & 8 & $\mathrm{WNW}$ \\
VF-74-129 & 4 & Lapilli & Quisache & 7.5 & $\mathrm{NW}$ \\
VF-74-136 & 4 & Lapilli & La Solcdad & 7 & $\mathrm{~N}$ \\
VF-74-134D & 5 & Bomb & Ojo dc Agua & 8.5 & $\mathrm{WNW}$ \\
VF-74-137B & 4 & Bomb & La Solcdad & 7 & $\mathrm{~N}$ \\
VF-74-R-134D & 5 & Rim & Ojo dc Agua & 8.5 & $\mathrm{WNW}$ \\
VF-74-R-137B & 5 & Rim & La Solcdad & 7 & $\mathrm{~N}$ \\
\hline
\end{tabular}




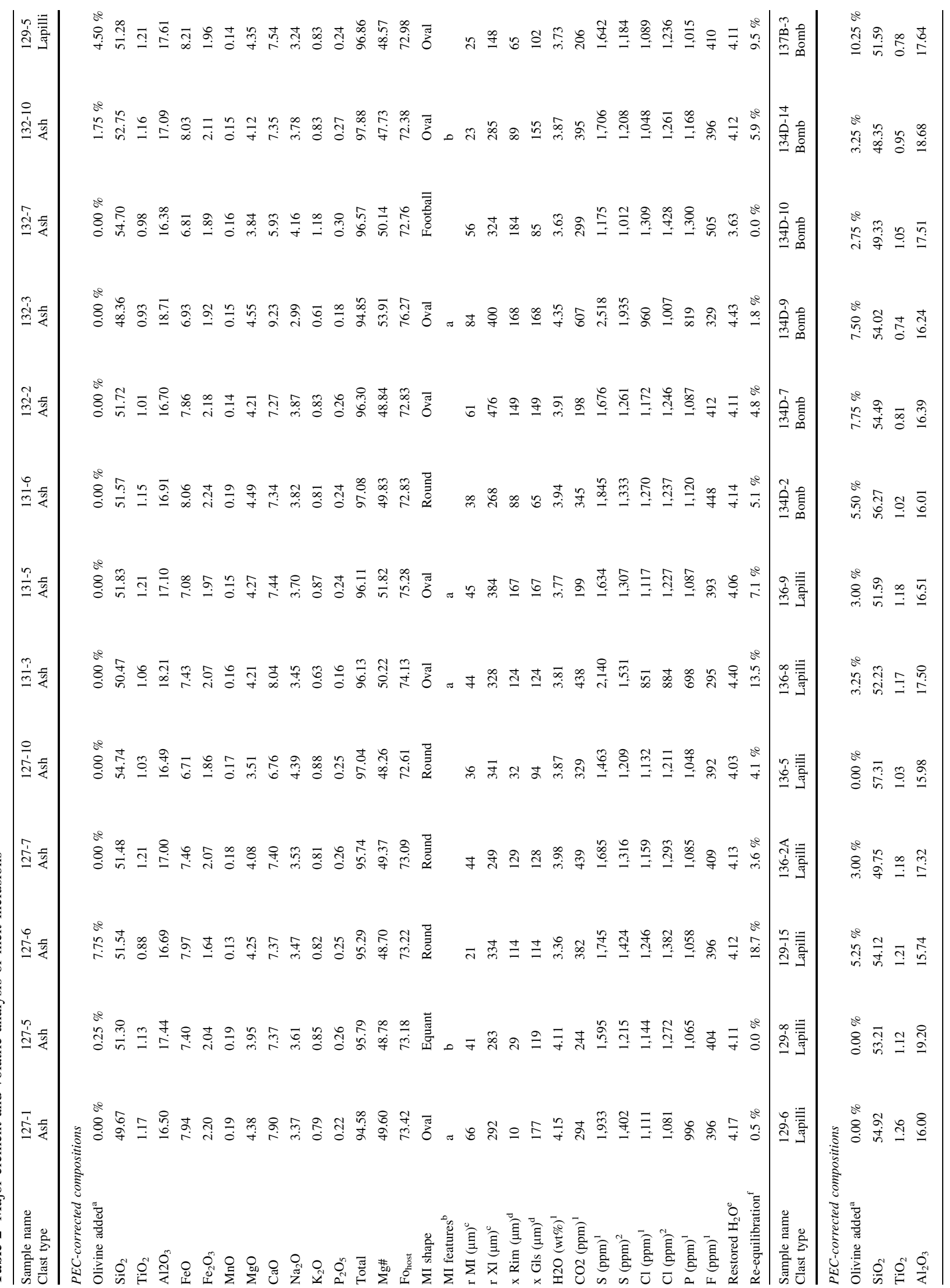




\begin{tabular}{|c|c|c|c|}
\hline लि & 过 & 寍注 & 光 \\
\hline ర్ & 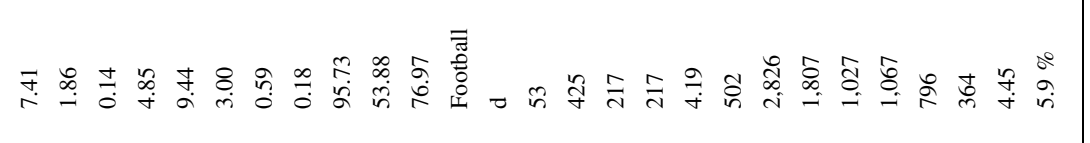 & 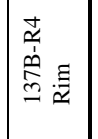 & 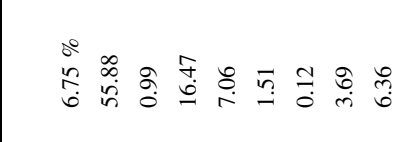 \\
\hline छे & ôे & 竞: & 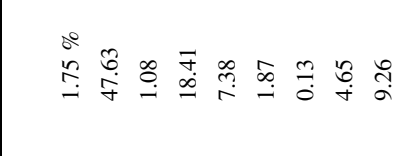 \\
\hline ह & 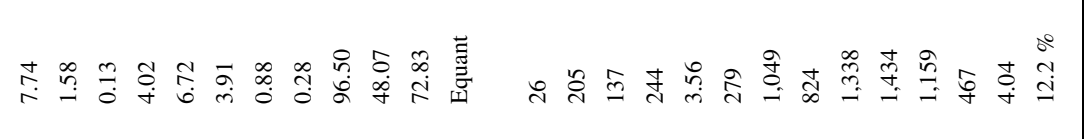 & 畺: & 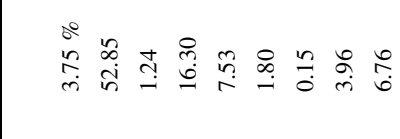 \\
\hline छ & 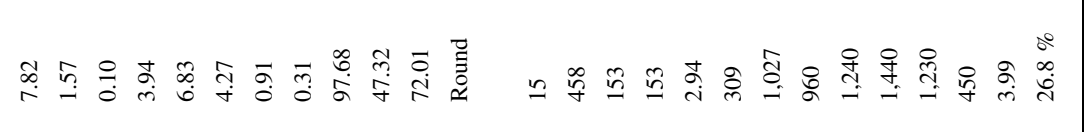 & 紊: & 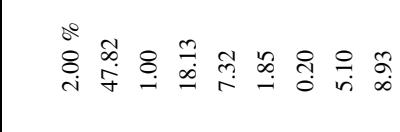 \\
\hline 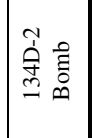 & 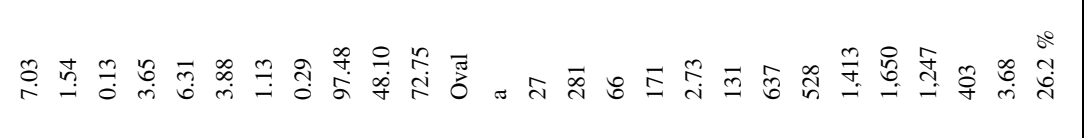 & 鸽园 & 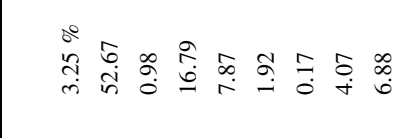 \\
\hline 害 & 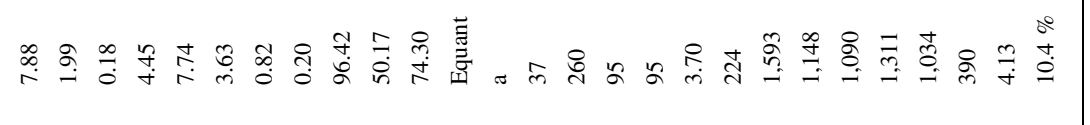 & 害园 & 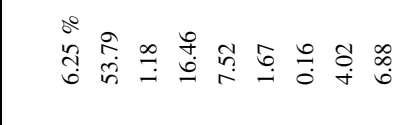 \\
\hline$\overline{\bar{z}}$ & 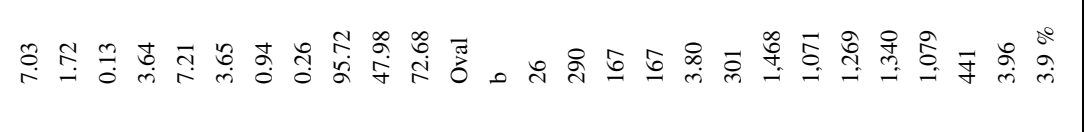 & 守 表 & 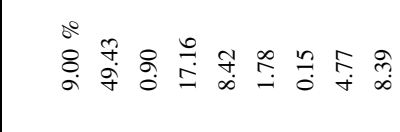 \\
\hline 言 & 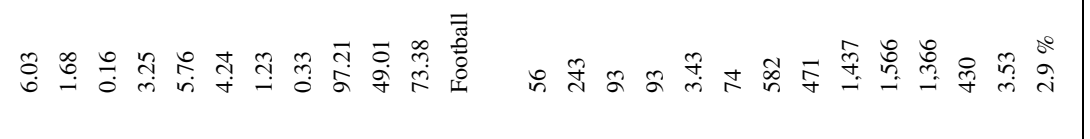 & 守空 & 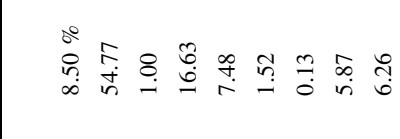 \\
\hline$\overline{\bar{\sigma}}$ & 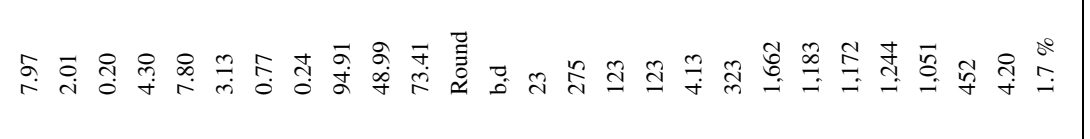 & 守表 & 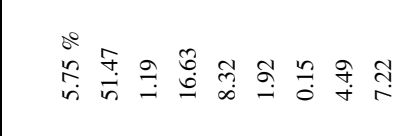 \\
\hline$\overline{\bar{z}}$ & 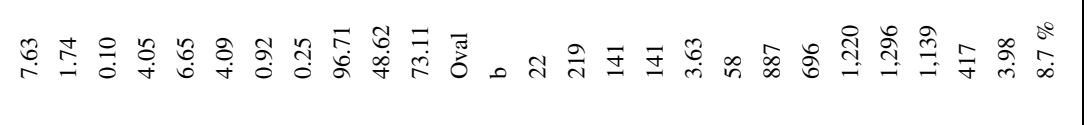 & 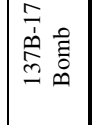 & 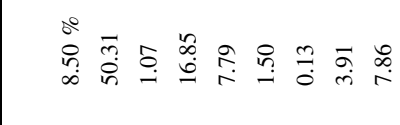 \\
\hline 言 & 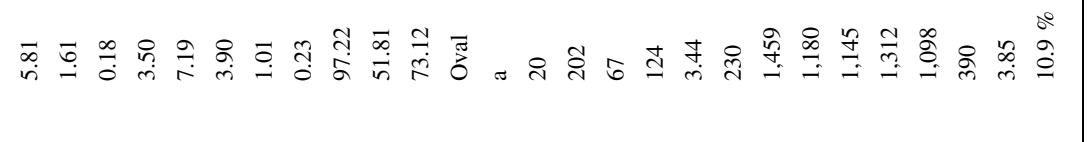 & 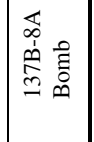 & 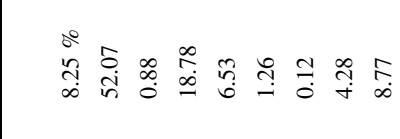 \\
\hline 言 & 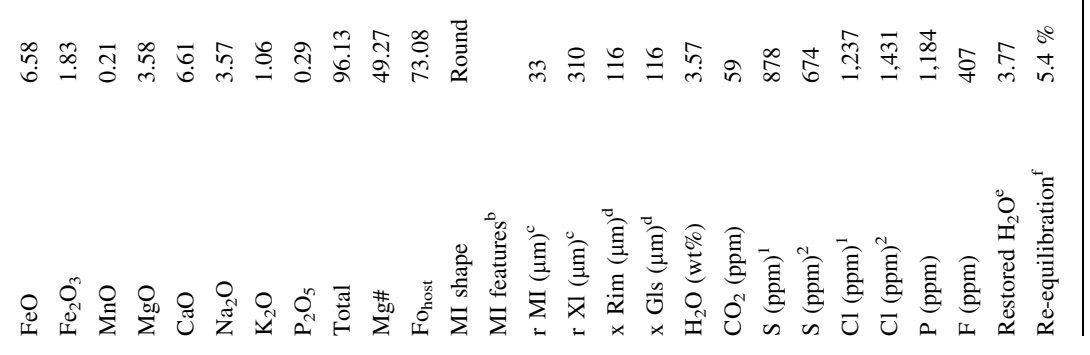 & $\mid$ & 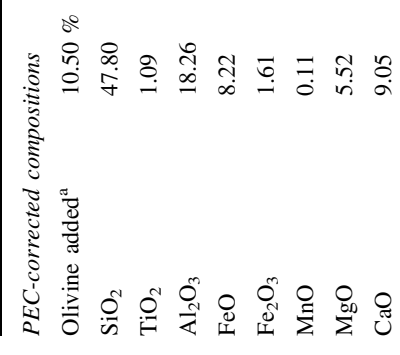 \\
\hline
\end{tabular}




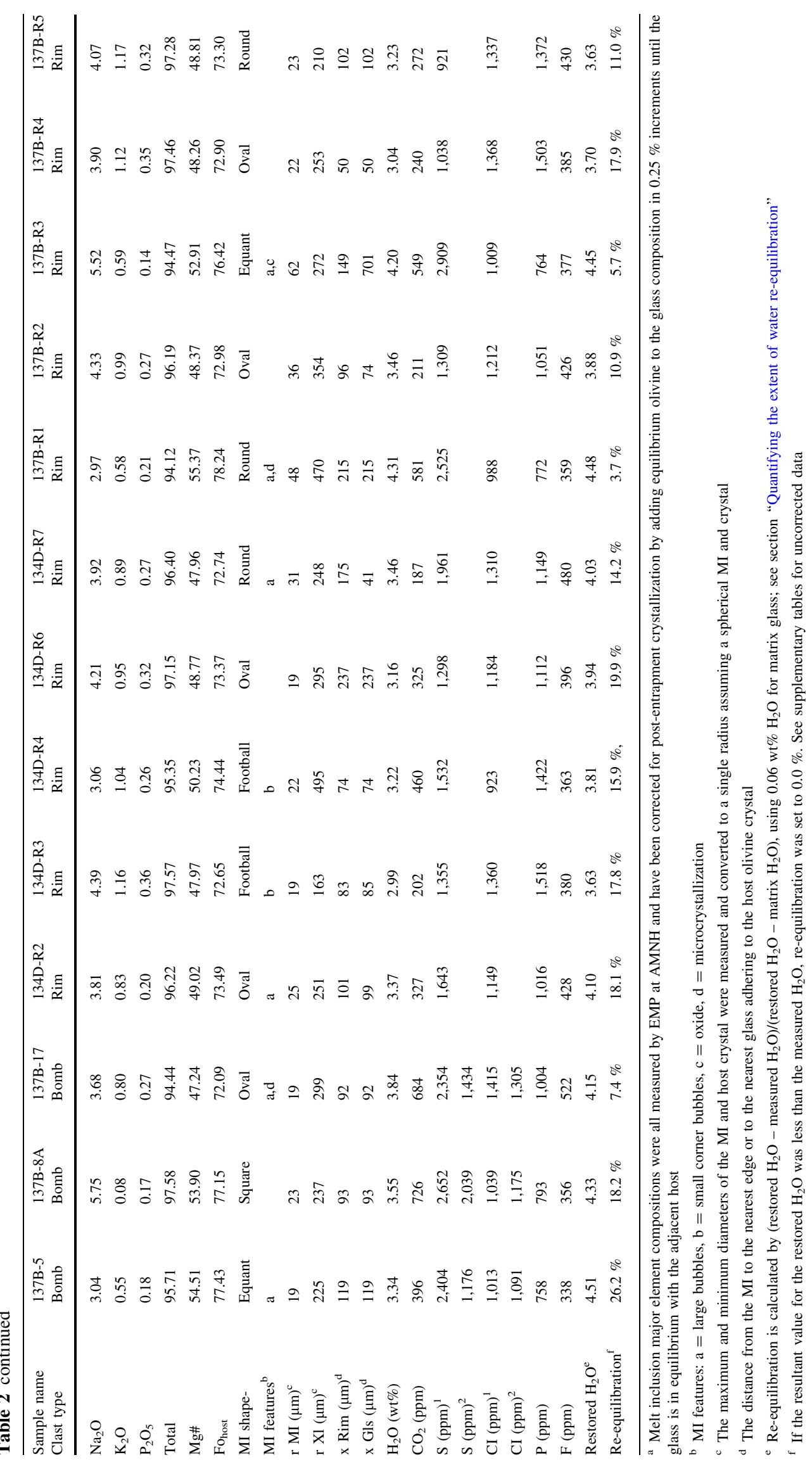


between 2 and $64 \mathrm{~mm}$ ), and two samples represented the bomb category (clasts with a diameter $>64 \mathrm{~mm}$ ). The ash samples $(127,131$, and 132) were sieved without crushing, and loose olivine grains were selected from $250-500-\mu \mathrm{m}-$ and 500-1,000- $\mu \mathrm{m}$-size fractions. Lapilli samples (129 and 136) were collected as a mix of ash and lapilli ranging in size from 30 to $<0.1 \mathrm{~mm}$. Only pyroclasts greater than $20 \mathrm{~mm}$ in diameter were selected, and of this set, the five largest lapilli were chosen (Table 1). Prior to crushing and sieving, $60-\mu \mathrm{m}$ sandpaper was used to remove the outer $\sim 1 \mathrm{~mm}$ rapidly cooled surface of the lapilli samples so as not to overlap with the cooling rates represented by the ash samples. Bomb samples (134D and 137B) were selected from a diverse set of collected bombs for their uniform spherical shape and large size (Table 1). Although the largest bombs were selected from the deposit, it is important to note that these are at the small end of what is considered a volcanic bomb ( $\sim 6 \mathrm{~cm}$ diameter). Each bomb was cut so that the material sampled for olivine-hosted MIs was the core of each bomb with $20 \times 20 \times 20 \mathrm{~mm}^{3}$ dimensions. The rims cut from the bombs ranged in size from 15 to $5 \mathrm{~mm}$ and were prepared separately from the core. Bomb rims share the same ascent history of the bomb cores, but experienced a different post-eruptive cooling rate. The cores and rims of the bombs were then crushed and sieved to the aforementioned sizes. The vesiculation in these pyroclasts was uniform between clast types and visually estimated to be $\sim 40 \%$; groundmass color was observed to be consistent among all the samples.

After crushing, olivine phenocrysts and fragments ( $\sim 10 \%$ by volume) were separated by hand from groundmass $(\sim 60 \%)$, plagioclase $(\sim 25 \%)$, opaque minerals $(3 \%)$, and clinopyroxene $(\sim 2 \%)$. Phenocrysts were then picked for analyzable MIs within olivine, which are relatively common in these deposits. Moreover, the Fuego MIs (from the ash and lapilli collections specifically) are generally glassy and have few bubbles, oxides, or other imperfections, which were carefully avoided in MI selection. Phenocrysts were mounted individually in dental resin and polished on one side until the melt inclusion was exposed, then removed from the resin, and mounted together in indium metal for SIMS (secondary ion mass spectrometer), EMP (electron micro-probe), and LA-ICPMS (laser inductively coupled mass spectrometer) analysis. Analysis of the MIs by SIMS was completed first, in order to avoid potential $\mathrm{H}_{2} \mathrm{O}$ loss during exposure to the electron beam and the possibility of $\mathrm{CO}_{2}$ contamination by the EMP carbon coat. After polishing, measurements were taken of the phenocryst size, the MI radius, and the distance from the MI to the nearest glassy rim surrounding the host phenocryst (Table 2). The size and position of these parameters in three-dimensional space are unknown.
Ion microprobe analyses

Volatiles $\left(\mathrm{H}_{2} \mathrm{O}, \mathrm{CO}_{2}, \mathrm{Cl}, \mathrm{F}\right.$, and $\left.\mathrm{S}\right)$ and $\mathrm{P}$ in the MIs were measured in two sessions on a Cameca IMS 6f ion probe (SIMS) at the Carnegie Institute of Washington (CIW), Department of Terrestrial Magnetism (Table 2). The procedures followed those in Hauri (2002), using a basaltic glass calibration curve and in all cases measuring $\mathrm{H}_{2} \mathrm{O}$ as ${ }^{16} \mathrm{O}^{1} \mathrm{H}$ and $\mathrm{CO}_{2}$ as ${ }^{12} \mathrm{C}$. A primary beam $(5-10 \mathrm{nA})$ accelerated to $10 \mathrm{kV}$ was used to create a $20-40-\mu \mathrm{m}$ spot size. In the first session, which covered the ash, lapilli, and bomb MIs, replicate analysis of four basaltic glass check standards (Fonualei Rift:ND-60-01 (10), Mangatolu Rift:ND-70-01 (8), JDF46 N (6), 892-1 (6); number of analyses in parenthesis) yielded average 2 relative standard deviations (standard deviation/average; 2RSDs) of $8.3 \%$ for ${ }^{12} \mathrm{C}, 8.3 \%$ for ${ }^{16} \mathrm{O}^{1} \mathrm{H}, 7.4 \%$ for $\mathrm{S}, 13.4 \%$ for $\mathrm{F}, 4.6 \%$ for $\mathrm{P}$, and $13.2 \%$ for $\mathrm{Cl}$. In the second session, which covered the rim MIs, replicate analysis of two basaltic glass check standards (FR:ND-60-01 (6), MR:ND-70-01 (6)) yielded average 2RSDs of $9.7 \%$ for ${ }^{12} \mathrm{C}, 4.2 \%$ for ${ }^{16} \mathrm{O}^{1} \mathrm{H}, 3.1 \%$ for $\mathrm{S}, 3.0 \%$ for $\mathrm{F}, 1.8 \%$ for $\mathrm{P}$, and $4.4 \%$ for $\mathrm{Cl}$ (see Supplement Table 1).

\section{Electron microprobe analyses}

MIs and olivine phenocrysts were analyzed for major elements using a Cameca SX100 microprobe (EMP) at the American Museum of Natural History (AMNH) during two sessions (Table 2 gives melt inclusion analyses and Fo content; individual olivine analyses are in Supplement Table 2). The analyses of the MIs were performed as close to the center of the inclusion as possible. The host olivine phenocryst was then analyzed within $20 \mu \mathrm{m}$ from the border with the melt inclusion.

During both sessions, major elements in hydrous glasses and olivine phenocrysts were analyzed using a 10-nA beam current (4-nA for $\mathrm{Na}$ ) and a $15-\mathrm{kV}$ accelerating potential with a $12-\mu \mathrm{m}$-diameter beam. Count times on peak for major elements were 30 and $15 \mathrm{~s}$ for backgrounds. $\mathrm{Na}_{2} \mathrm{O}$ was counted for $2 \mathrm{~s}$ on peak and $20 \mathrm{~s}$ on background; $\mathrm{FeO}_{\mathrm{T}}$ count times were $20 \mathrm{~s}$ on peak and $15 \mathrm{~s}$ for background. During the first session when the ash, lapilli, and bomb samples were analyzed, replicate analysis of four basaltic glass check standards (FR:ND-60-01 (2), MR:ND-70-01 (3), JDF46 N (2), 892-1 (2)) yielded an average 2RSD of $9.4 \%$ for $\mathrm{K}_{2} \mathrm{O}$ and $<10 \%$ for the remainder of the major elements (excluding $\mathrm{MnO}$ and $\mathrm{P}_{2} \mathrm{O}_{5}$; both with $\sim 30 \%$ ). Both $\mathrm{S}$ and $\mathrm{Cl}$ were measured by EMP and SIMS, with excellent correspondence between the two techniques $\left(R^{2}\right.$ values of 0.94 and 0.76 , respectively) but a consistent slope offset of 1.3 for $\mathrm{S}$ and 0.9 for $\mathrm{Cl}$ (SIMS/EMP). Sulfur was measured on the sulfate peak position and was standardized on $\mathrm{BaSO}_{4}$. During the second 
session when the rim samples were analyzed, replicate analysis of two basaltic glass check standards (FR:ND-60-01 (5), MR:ND-70-01 (5); Supplement Table 3) yielded an average $2 \mathrm{RSD}$ of $6.8 \%$ for $\mathrm{K}_{2} \mathrm{O}$ and $<12 \%$ for the remainder of the major elements (excluding $\mathrm{Na}_{2} \mathrm{O}, \mathrm{MnO}$, and $\mathrm{P}_{2} \mathrm{O}_{5}$ : $24.2,37.0$, and $64.8 \%$, respectively). To correct for inter-run calibration offsets, all analyses were corrected using factors determined from eight MI replicate analyses and the accepted values for the FR:ND-60-01 and MR:ND-70-01 basaltic check standards (values from C. Mandeville, personal communication; see Supplement Table 4 for procedure and correction factors).

\section{Laser ablation ICP-MS analyses}

Melt inclusions and olivine phenocrysts were analyzed at the Lamont-Doherty Earth Observatory of Columbia University using an ESI/New Wave UP193-FX laser ablation system coupled to a VG PQ ExCell quadrupole ICP-MS (MIs in Supplement Table 5; Olivine in Supplement Table 6). Samples were ablated in a $\mathrm{He}-\mathrm{Ar}$ mixture at a flow rate of $0.6 \mathrm{~mL} / \mathrm{min}$ for Ar and $1.6 \mathrm{~mL} / \mathrm{min}$ for He. During melt inclusion analysis, the laser was operated in spot-drill mode at $10 \mathrm{~Hz}$ and at $70 \%$ power, for an average energy density of $11.3 \mathrm{~J} / \mathrm{cm}^{2}$ and irradiance of $2.26 \mathrm{GW} / \mathrm{cm}^{2}$. The dwell time for all elements was $10 \mathrm{~ms}$. Spot sizes were adjusted using the iris and varied between 40 and $85 \mu \mathrm{m}$ to maximize area within each inclusion. The laser data were acquired in timeresolved mode and calibrated against USGS glasses BHVO$2 \mathrm{G}, \mathrm{BCR}-2 \mathrm{G}$, and BIR-1G (using $75 \mu \mathrm{m}$ spots, and values in Kelley et al. 2003), with ${ }^{49} \mathrm{Ti}$ as the internal standard. The average precision for five replicate analyses of BCR-2G over the course of the 5 -h session was $<8 \% 2 \mathrm{RSD}$ for all elements (Supplement Table 7).

During olivine phenocryst analysis, the laser was operated in raster mode at $10 \mathrm{~Hz}$ and at $70 \%$ power, for an average energy density of $10.7 \mathrm{~J} / \mathrm{cm}^{2}$ and irradiance of $2.15 \mathrm{GW} / \mathrm{cm}^{2}$. The dwell time for all elements was $10 \mathrm{~ms}$. The beam was set to $25 \mu \mathrm{m}$ width and rastered at a rate of $3 \mu \mathrm{m} / \mathrm{s}$. The laser data were acquired in time-resolved mode and calibrated against USGS glasses BHVO-2G, BCR-2G, BIR-1G, and San Carlos olivine (values in Kelley et al. 2003), with ${ }^{26} \mathrm{Mg}$ as the internal standard. The average precision for three replicate analyses of San Carlos olivine over the course of the $4 \mathrm{~h}$ session was $<8 \%$ 2RSD for all elements (Supplement Table 7).

\section{Results}

Melt inclusion population

We report analyses from 39 MIs from the October 17, 1974, eruption including 12 from three ash locations, 8 from five lapillus clasts, 9 from two bombs, and 10 from the rims of the two bombs (Table 1). The MIs analyzed from the ash samples are larger on average ( $48 \mu \mathrm{m}$ radius) than those from the bomb, lapilli, and bomb rim samples $(29,33$, and $31 \mu \mathrm{m}$, respectively). This sample bias was not intentional and resulted from the availability of glassy inclusions that met the requirement for a minimum radius of $20 \mu \mathrm{m}$ and were minimally crystallized or devitrified. Ash samples tended to contain fewer devitrified MIs, likely due to the faster cooling rate, which leads to a faster quenching rate of the inclusion and less post-entrapment crystallization. With the availability of both large and small inclusions, larger inclusions are favored because they are easier not only to prepare, but also to analyze. On the other hand, MIs from the more slowly cooled bomb and lapilli samples showed greater degrees of post-entrapment alteration, including devitrification, microlite growth, and softening/rounding of inclusion walls (Fig. 1). This was particularly true for the larger inclusions, and so we were constrained by quality to select smaller inclusions for the analysis of the lapilli, bombs, and rims. Besides the radius of the MIs, there was no other systematic inter-clast variability. MI shapes ranged from spherical to angular inverse crystal forms, and the color of the brown glass was relatively uniform. While inclusions with sharp or faceted edges generally preserved the highest $\mathrm{H}_{2} \mathrm{O}$ contents (and were more common in ash samples), visual features alone are insufficient to predict which MIs will contain more water than others. It should be noted that 22 of the 39 reported MIs contained either vapor bubbles or small corner bubbles (Table 2); however, bubbles volumes were small in comparison with the MI. The largest vapor bubble found had a $24-\mu \mathrm{m}$ radius in an $84-\mu \mathrm{m}$-radius MI. The maximum vapor bubble volume/MI volume ratio measured was $4.36 \%$. There was no correlation found between water loss and the size or presence of a vapor bubble.

Major element concentrations in melt inclusions and olivines

It is important to consider how close the melt inclusions are to equilibrium with their host olivine, and how similar their compositions are to the host magma, as such comparisons offer important clues for pre- and post-entrapment processes (Danyushevsky et al. 2000). An assessment of equilibrium between MI and olivine can be made by assuming a partition coefficient $\left(K_{D}\right)$ for $\mathrm{Fe}^{2+} / \mathrm{Mg}$ exchange between ol/liq (calculated here as 0.35 , using the expressions in Toplis 2005), but this exercise also depends on how much of the total $\mathrm{Fe}$ might be $\mathrm{Fe}^{2+}$. Because there are no direct measurements of the $\mathrm{Fe}^{3+} / \mathrm{Fe}^{2+}$ ratio in the magma, this needs to be deduced from other considerations. The first is based on partitioning of $\mathrm{V}$ between melt 
Fig. 1 A comparison of olivine-hosted melt inclusions (MIs) from the ash and bomb sample suites. The ash MI shows a sharper boundary, whereas the bomb MI exhibits a more diffuse boundary, possibly reflecting the varying cooling history. Both MIs have similar $\mathrm{S}, \mathrm{CO}_{2}$, and $\mathrm{K}_{2} \mathrm{O}$ concentrations but differ in $\mathrm{H}_{2} \mathrm{O}$, which we interpret as diffusive loss through the bomb olivine. Reequilibration in the bomb MI is a function of both a slower cooling rate and in this case a smaller radius

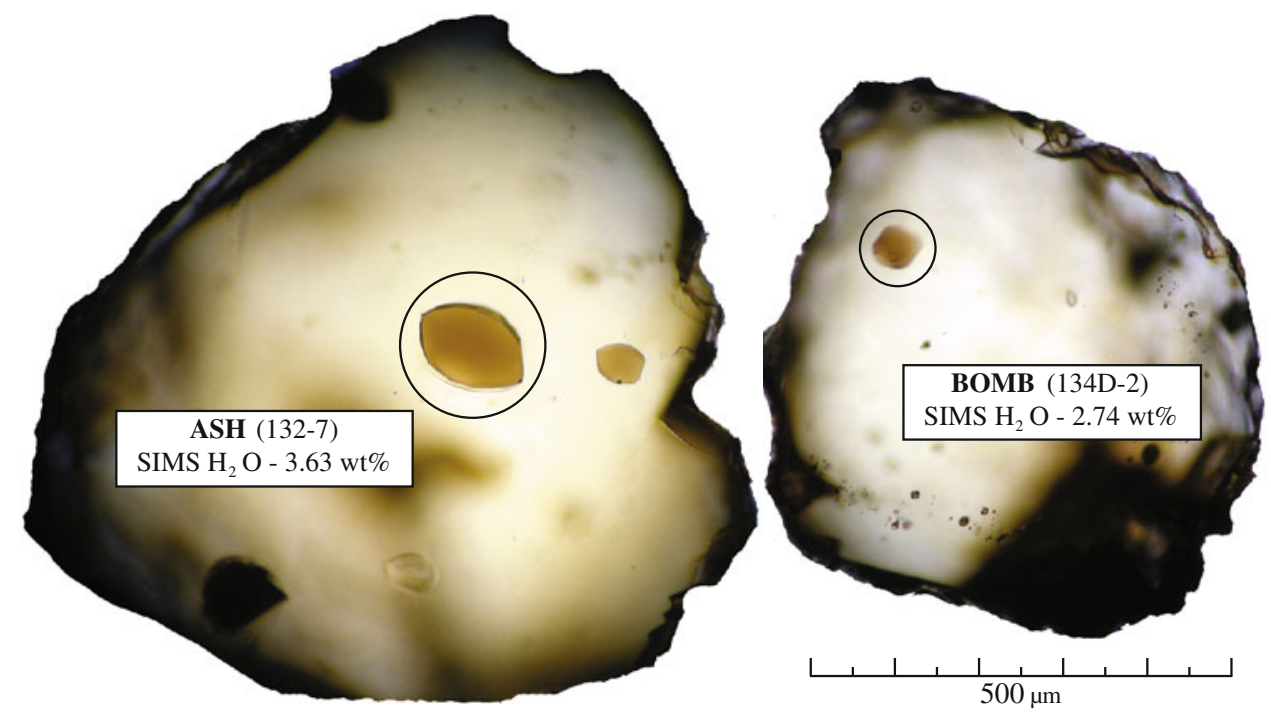

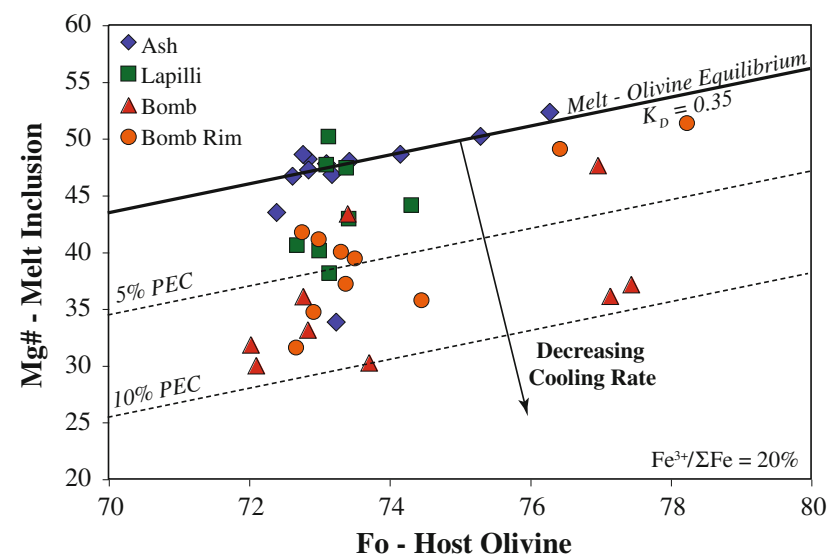

Fig. $2 \mathrm{Mg} \#\left(\mathrm{Mg} /\left[\mathrm{Mg}+\mathrm{Fe}^{2+}\right]\right)$ of melt inclusions (MIs) plotted against host olivine forsterite content $(\mathrm{Fo}=\mathrm{Mg} \#$ in the olivine). MIs $\mathrm{Mg} \#$ have been calculated assuming $20 \% \mathrm{Fe}^{3+} / \Sigma \mathrm{Fe}$. (see text). The contours show the amount of post-entrapment crystallization correction necessary to return the MIs to equilibrium with their host crystals. The MIs from the bomb and bomb rim samples show the greatest $\mathrm{PEC}$, which is consistent with a longer cooling time

and olivine, which has been calibrated as an oxybarometer by Canil (2002) and compared directly to uXANES $\mathrm{Fe}^{3+}$ / $\Sigma$ Fe measurements by Kelley and Cottrell (2012). We use $\mathrm{V}$ concentrations in eleven Fuego MIs and their corresponding host olivines (Supplement Table 8) to arrive at $f \mathrm{O}_{2}$ estimates of $1.2 \mathrm{log}$ units above the FMQ buffer $(\Delta \mathrm{FMQ}=+1.2)$ for the more mafic phenocrysts $\left(\mathrm{Fo}_{77-78}\right)$ and $\triangle \mathrm{FMQ}$ of +0.76 for $\mathrm{Fo}_{73-74}$ phenocrysts (Fig. 3). A similar range in $f \mathrm{O}_{2}$ is deduced from the sulfur concentration of MIs, and applying the model of Jugo et al. (2010) for sulfide-saturated melts (Fuego samples contain visible immiscible sulfide, as inclusions in olivine, Rose et al. 1978, and in clinopyroxene and magnetite, from our own observations). Fuego MIs trapped in higher Fo olivines (>76) average 2,600 ppm S $(\sim \Delta \mathrm{FMQ}+1)$ while the $\mathrm{MI}$ in lower Fo olivines (72-74) average 1,500 ppm S $(\Delta \mathrm{FMQ} \leq+0.5)$. The lower oxidation state reflected in both the $V$ partitioning and $S$ concentrations of the more evolved melts could relate to magnetite fractionation and/ or sulfur degassing (see Kelley and Cottrell 2012, for a similar trend). This range in $f \mathrm{O}_{2}$ would yield $\mathrm{Fe}^{3+} / \Sigma \mathrm{Fe}$ in the melt of 18-23\% (using the model in Kress and Carmichael 1991).

Bearing these considerations in mind, we found that most of the MIs from the ash samples form an array that parallels the olivine-equilibrium line in Fig. 2, and overlies it if the melt contains $20 \% \mathrm{Fe}^{3+} / \Sigma \mathrm{Fe}$. Thus, most of the melt inclusions from the ash samples appear to be erupted in equilibrium with their host olivines. Melt inclusions that lie below the equilibrium line in Fig. 2 likely experienced post-entrapment crystallization (PEC) of olivine (Sisson and Layne 1993; Danyushevsky et al. 2000), and so these compositions were restored, as is typically done, by adding equilibrium olivine incrementally to the MI composition until equilibrium is reached with the host phenocryst immediately adjacent to the MI. The average amount of olivine added to the MIs increases from ash $(0.8 \mathrm{wt} \%)$, to lapilli $(2.4 \%)$, to rim $(5.1 \%)$, to bomb $(7.2 \%)$ samples (Table 2), although most of the MIs that require $>8 \%$ PEC are from the bomb samples. These differences are in the direction expected for slower cooling, with more time for crystallization of olivine on the inclusion wall in lapilli and bomb samples. Post-entrapment crystallization could be driven additionally by $\mathrm{H}_{2} \mathrm{O}$ loss from the inclusion, due to the rise in the olivine-liquidus temperature (Danyushevsky et al. 2002). Various cooling and water loss scenarios were simulated in Petrolog (Version 3.0; Danyushevsky and Plechov 2011) to test whether the slower cooling rate or the effect of water loss were responsible for the additional PEC observed in the bomb MIs. Results indicated that a loss of 


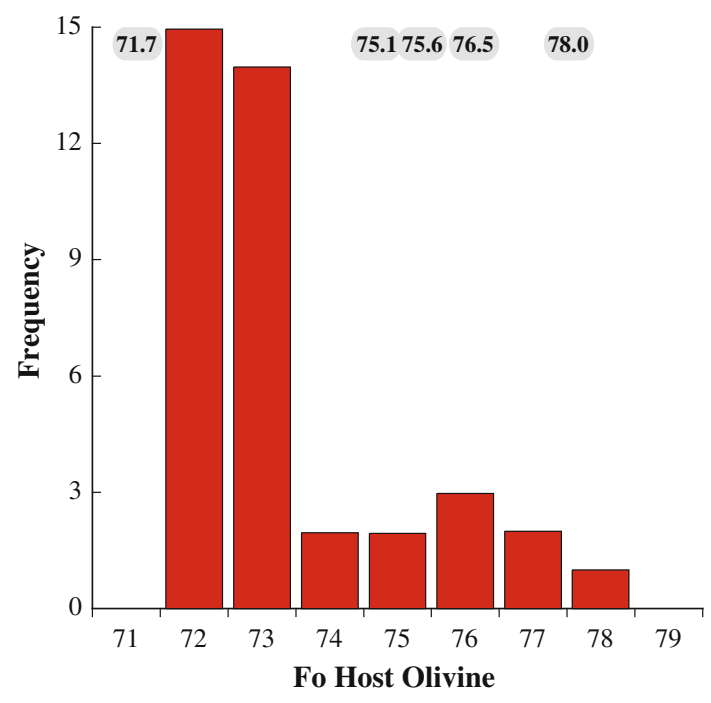

Fig. 3 Histogram of the olivine phenocrysts erupted on October 17. All olivines were analyzed in the vicinity of melt inclusions and generally characterize the composition of the crystal core. The gray bubbles represent the Fo in equilibrium with whole rock analyses (Rose et al. 1978) of bulk ash erupted on October 17

$1 \mathrm{wt} \% \mathrm{H}_{2} \mathrm{O}$ (the maximum observed, see below) would drive only 1-2 wt\% olivine crystallization; therefore, slower cooling rates in bomb MIs are likely responsible for most of the observed PEC. The MIs, in general, do not reflect the kind of $\mathrm{Fe}$ loss re-equilibration that characterizes much more slowly cooled samples (Danyushevsky et al. 2000).

The range in olivine compositions that host melt inclusions falls between $\mathrm{Fo}_{72}$ and $\mathrm{Fo}_{78}$ with the majority being between $\mathrm{Fo}_{72}$ and $\mathrm{Fo}_{74}$ (Fig. 3). This range is expected given the bulk ash samples analyzed by Rose et al. (1978), which vary in $\mathrm{Mg \#}$ as much as the melt inclusions, and predicts a nearly identical range in equilibrium olivines $\left(\mathrm{Fo}_{71.7}-\mathrm{Fo}_{78}\right.$, assuming the same $\mathrm{K}_{\mathrm{D}}$ and $\mathrm{Fe}^{3+}$ values as above). The average of the bulk ash samples is skewed (Fig. 3), however, to higher $\mathrm{Mg \#}$ (equilibrium with $\mathrm{FO}_{75-78}$ ) compared with the melt inclusions (most at $\mathrm{Fo}_{72-74}$ ). Despite this diversity of olivines and the skewed populations, there is no obvious relationship between Fo content of the host olivine and the PEC effects discussed above. Within the five MIs hosted in higher Fo olivines, the ash MIs fall on the equilibrium line and the three bomb MIs require up to $10 \%$ PEC. Thus, post-entrapment crystallization affects both populations $\left(\mathrm{Fo}_{72}-\mathrm{Fo}_{74}\right.$ and $\left.>\mathrm{Fo}_{74}\right)$ of the bomb MIs in a similar way. Of the 21 phenocrysts that were rastered and analyzed by LA-ICP-MS (see Supplement Table 6 and Supplement Figure 1), thirteen are effectively unzoned (variation less than one Fo unit from core to rim). Seven phenocrysts are normally zoned in Fo values, while only one is reversely zoned. The phenocryst that shows the maximum decrease in Fo is bomb sample
134D-14, with a decrease from $\mathrm{Fo}_{78}$ to $\mathrm{FO}_{74}$ over a $425-\mu \mathrm{m}$ raster from core to rim. The higher Fo olivines tend to show the greatest zonation, but there is no correlation with clast size.

Major elements in the melt inclusions are broadly consistent with crystal fractionation of the observed phenocryst phases in the 1974 magma $(\mathrm{ol}+\mathrm{pl}+\mathrm{cpx}+\mathrm{mt})$. After correction for PEC, most of the MIs decrease in $\mathrm{Al}_{2} \mathrm{O}_{3}$ and $\mathrm{CaO}$ with decreasing $\mathrm{MgO}$ (Fig. 4a, b), consistent with crystallization of the observed phenocrysts. The slope of the trends is consistent with that of a calculated 4-phase cotectic (see Fig. 4 for details). The weighted bulk ash of the entire 1974 eruption (Rose et al. 1978) also plots near/on the MI array; however, most of the individual bulk ash samples (particularly those from October 17) plot at distinctly higher $\mathrm{Al}_{2} \mathrm{O}_{3}$ and $\mathrm{CaO}$ than the MIs (Fig. 4a, b). The question then becomes whether the melt inclusions or the bulk ash better represent the differentiating Fuego liquid. Both kinds of samples can have issues that render them poor proxies of magmatic liquids. Bulk ash can contain excess crystals, and melt inclusions can be driven toward anomalous compositions during exchange through crystals or entrapment of boundary-layer or mush melts (Danyushevsky et al. 2004; Baker 2008). The October 17 bulk ash contains $20-40 \%$ crystals (Rose et al. 1978), most of which are plagioclase, and so excess crystals are a distinct possibility. A recently developed Al-hygrometer predicts the maximum $\mathrm{Al}_{2} \mathrm{O}_{3}$ content attained along a liquid line of descent (LLD) as a function of $\mathrm{H}_{2} \mathrm{O}$ concentrations dissolved in the melt (Parman et al. 2011). The principle behind this is the suppression of plagioclase crystallization by water; the appearance of plagioclase on the cotectic is delayed in wetter magmas, and so $\mathrm{Al}_{2} \mathrm{O}_{3}$ is driven to higher concentrations at the point of plagioclase saturation. According to the formulation in Parman et al. (2011; equation in their Fig. 4 caption), magmas with $4.5 \mathrm{wt} \% \mathrm{H}_{2} \mathrm{O}$ (like Fuego October 17) reach a maximum $\mathrm{Al}_{2} \mathrm{O}_{3}$ concentration of $19 \%$, when plagioclase appears on the cotectic. This $\mathrm{Al}_{2} \mathrm{O}_{3}$ is completely consistent with the melt inclusion array, but not the bulk ashes, which extend up to $21-22 \% \mathrm{Al}_{2} \mathrm{O}_{3}$. We thus consider the melt inclusions to be more representative of Fuego liquids than the bulk ashes, which contain excess plagioclase crystals, in particular.

Figure $4 \mathrm{~d}$ presents a compilation of $\mathrm{SiO}_{2}$ and $\mathrm{K}_{2} \mathrm{O}$ in $\mathrm{MI}$ and bulk ashes from the 1974 eruption at Fuego. On an anhydrous basis, the October 17 MIs range from 50 to $59 \mathrm{wt} \% \mathrm{SiO}_{2}$ (basalt to andesite) and vary more than a factor of two in $\mathrm{K}_{2} \mathrm{O}(0.55-1.25$; Fig. $4 \mathrm{c})$. The bomb and rim MIs include the most mafic melts, and the lapilli MIs include the most felsic; however, the averages of MIs from the different clasts are the same within uncertainty, and the MI population as a whole forms a coherent trend. The bulk 

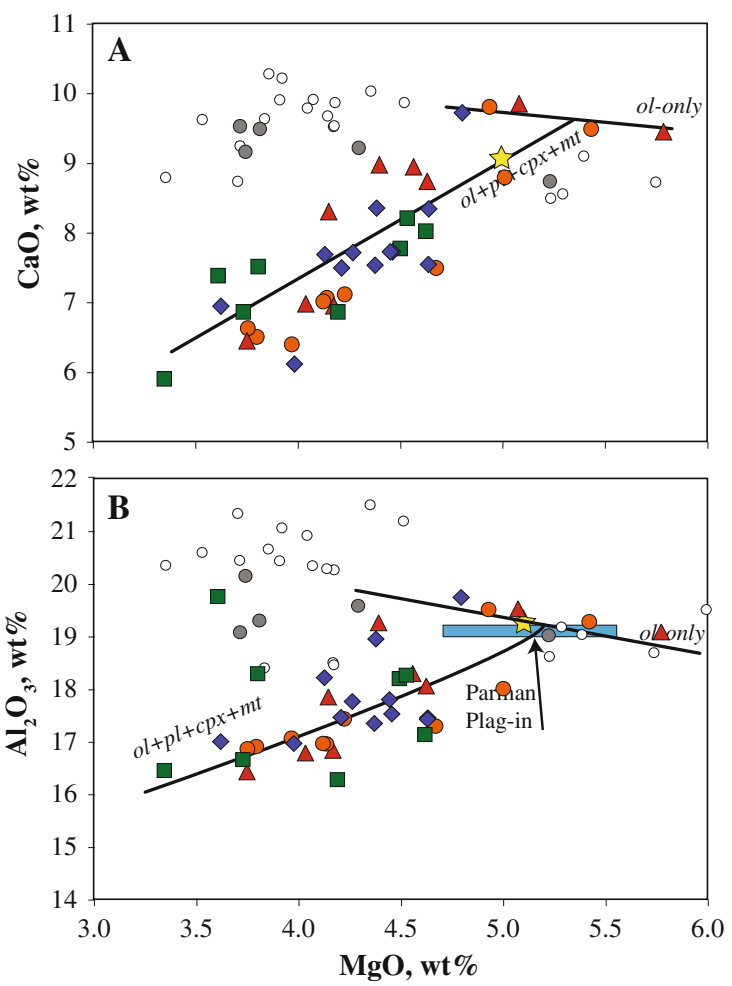

Fig. 4 Major element variations in melt inclusions (colored symbols) versus bulk ash from the 1974 eruption. All MIs are corrected for PEC, and both MIs and bulk ash are plotted anhydrous. In a and $\mathbf{b}$, cotectic trajectories for $\mathrm{ol}+\mathrm{pl}+\mathrm{cpx}+\mathrm{mt}$ crystallization are calculated from Petrolog3: decompressing 30 bars/degree ( 2.0-1.0 kbar, 1,030-980 ${ }^{\circ} \mathrm{C}$ ). $\mathrm{Al}_{2} \mathrm{O}_{3}(\max )$ at "Plag-in" is calculated from Parman et al. (2011) for $4.5 \mathrm{wt} \% \mathrm{H}_{2} \mathrm{O}$. The yellow star is the weighted average composition of all 1974 bulk ash, from Rose

ashes from the October 17 eruption vary substantially less, from 51.6 to $53.0 \mathrm{wt} \% \mathrm{SiO}_{2}$ and $0.77-1.1 \mathrm{wt} \% \mathrm{~K}_{2} \mathrm{O}$, and are somewhat offset from the MIs to lower $\mathrm{SiO}_{2} /$ higher $\mathrm{K}_{2} \mathrm{O}$. One difference, again, may be due to the high crystal content of the bulk ash samples (Fig. 4c). The differences, however, are subtle, and not reflected in ratios of incompatible trace elements (which are similar in the inclusions and bulk ashes, see below), and thus not due to different primary magmas, but more likely due to small differences in the proportion of fractionating phases that affect how $\mathrm{SiO}_{2}$ evolves as a function of melt fraction (which will largely control $\mathrm{K}_{2} \mathrm{O}$ ).

The wide range in $\mathrm{K}_{2} \mathrm{O}$ in Fuego melt inclusions has been noted in prior work (Rose et al. 1978; Berlo et al. 2012) and was not found to relate to crystal host size (Roggensack 2001a). It is clear from the $>2 \times$ range in $\mathrm{K}_{2} \mathrm{O}$ in the basaltic $\mathrm{MI}\left(<51 \% \mathrm{SiO}_{2}\right)$ that multiple magmas fed the 10-day eruption. Previous workers also emphasized a bimodal distribution in the melt inclusion $\mathrm{K}_{2} \mathrm{O}$ concentrations, with one peak at $\sim 0.6 \mathrm{wt} \% \mathrm{~K}_{2} \mathrm{O}$ and the other at $\sim 0.9$ wt $\% \mathrm{~K}_{2} \mathrm{O}$ (Roggensack 2001a; Berlo et al. 2012). Such bimodality, however, is less clear given the full
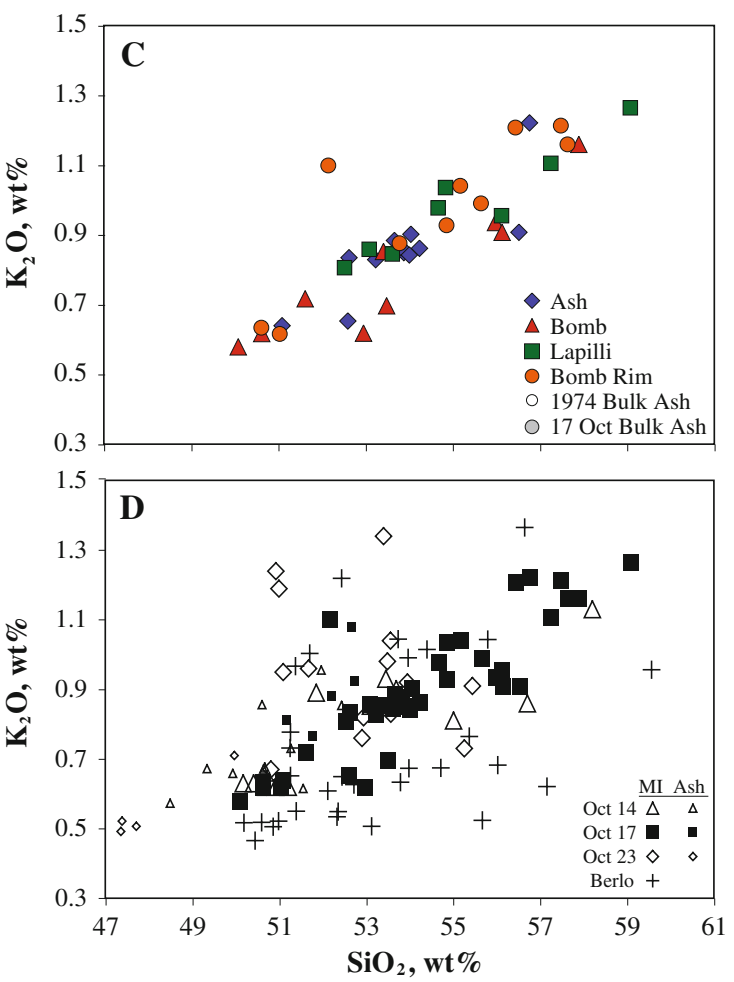

et al. (1978). d Highlights the intra-eruption variability of the 1974 Fuego eruption. The MIs from October 17 (closed symbols) define a single liquid line of descent for the samples used in this study. References for d: October 14 MIs from Sisson and Layne 1993 (S\&L) and Roggensack (Rogg) (2001a); October 17 MIs from this work and Rogg (2001); October 23 MIs from S\&L (1993); Berlo et al. (2012). All ash data from Rose et al. (1978)

dataset (Fig. 4d). In particular, our MI data from October 17 define a continuous linear trend, with some outliers, but no strong modes or end members present. There are also no obvious differences between the melt sampled by the bomb clasts versus those by the ash; both span the full range of $\mathrm{SiO}_{2}$ and $\mathrm{K}_{2} \mathrm{O}$ along the entire trend. Thus, while multiple magmas may have existed in the conduit and hybridized prior to and during the 1974 eruptions, the October 17 magma studied here does not appear to have sampled the full diversity present in the 1974 system. Instead, the October 17 MIs are consistent with a single liquid line of descent from a common parent. Perhaps the single parent is related to a fresh influx of basalt that fueled the explosive October 17 eruption, while the other less explosive eruptions included more magma resident in the plumbing system (Berlo et al. 2012).

Trace element concentrations in melt inclusions

The trace element concentrations in the MIs, as determined by laser ablation ICP-MS, generally support the inferences from the major elements, above. Most of the incompatible 


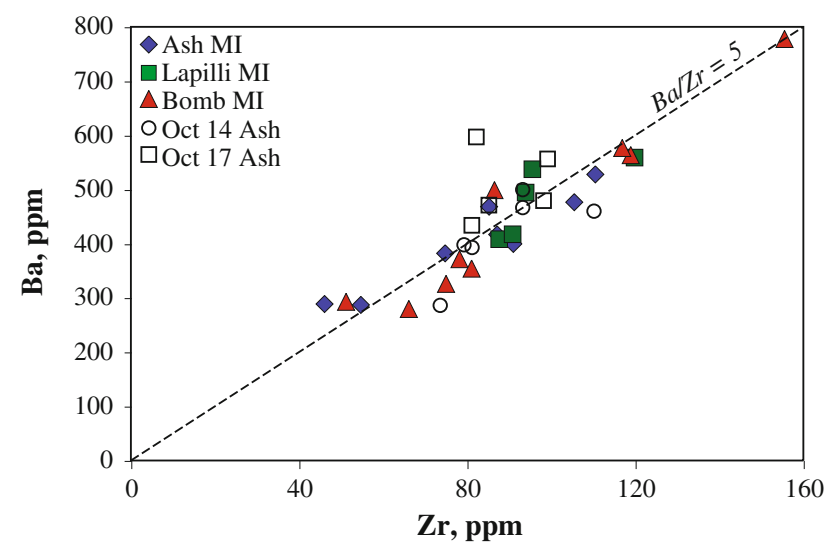

Fig. 5 Trace element concentrations of October 17 Fuego olivinehosted melt inclusions, determined by LA-ICPMS (Supplement Table 5), compared with bulk ash data. $\mathrm{Ba}$ and $\mathrm{Zr}$ are both incompatible elements, maintaining a constant ratio during crystal fractionation. The similar ratio in melt inclusions from ash, lapilli and bomb samples support a similar parental magma for each as well as for the bulk ash (open circles and squares; Rose et al. 1978; and Carr and Rose 1987)

elements correlate with $\mathrm{K}_{2} \mathrm{O}$ and show a total range of variation that is consistent with their compatibility. For example, the light rare earth elements (LREE), $\mathrm{P}, \mathrm{Nb}, \mathrm{Pb}$, $\mathrm{Ba}$, and $\mathrm{Zr}$, vary by a factor of $\sim 2$ similar to $\mathrm{K}_{2} \mathrm{O}$, while more incompatible elements vary by almost a factor of 3 $(\mathrm{Rb}, \mathrm{U}, \mathrm{Th})$, and more compatible elements $(\mathrm{Sr}, \mathrm{Ti})$ vary less. Thus, the trace elements are highly systematic with respect to their predicted compatibility in the crystallizing assemblage. Moreover, the ratio of incompatible elements is nearly constant in the MIs, supporting a similar parental magma. For example, the $\mathrm{Ba} / \mathrm{Zr}$ ratio is identical within the ash, lapilli, and bomb MIs $(5.0 \pm 2 \%$ for the group averages; Fig. 5). The MIs actually vary less than the bulk ash samples from October $17(\mathrm{Ba} / \mathrm{Zr}=5.8 \pm 16 \%)$ and only range from 4.3 to 6.3 versus 3.1 to 7.3 in Fuego eruptives as a whole (Carr and Rose 1987). Thus, the trace elements support a co-magmatic origin of the melt inclusions and do not include the diversity common in high-Fo olivines suites (Sisson and Bronto 1998; Danyushevsky et al. 2003; MacLennan et al. 2003).

\section{Volatile concentrations in melt inclusions}

The October 17 melt inclusions analyzed by SIMS in this study have comparable volatile concentrations, but vary less than those from other studies. Roggensack (2001a) analyzed inclusions from the initial phases of the eruption (primarily October 14), and found comparable $\mathrm{H}_{2} \mathrm{O}$ concentrations (measured by Fourier transform infrared spectroscopy) to those analyzed here, ranging from 3.0 to $4.5 \mathrm{wt} \% \mathrm{H}_{2} \mathrm{O}$ (Fig. 6a). Sisson and Layne (1993) and Berlo et al. (2012), however, report significantly higher $\mathrm{H}_{2} \mathrm{O}$ concentrations (4.5-6 wt\%) in both their October 14 and October 23 MIs. Thus, either $\mathrm{H}_{2} \mathrm{O}$ varies on different days of the eruption (although this is not apparent in unreported samples we analyzed), or there is an analytical offset in the pioneering ion probe analyses reported by Sisson and Layne (1993) or an inter-laboratory offset in the case of Berlo et al. (2012). Sulfur concentrations also show a significant difference between the different studies (Fig. 6b). Roggensack's October 14 inclusions notably range up to very high sulfur concentrations (4,000-5,000 ppm, which are high globally, Wallace 2005), while none of Sisson and Layne's October 14 inclusions contain $>1,500 \mathrm{ppm}$ (although none extend to such mafic compositions either; Fig. 6b). A matrix glass sample from Roggensack's study (2001a) also contains 2,000 ppm S, which is unusual given that matrix glass is typically degassed in sulfur (as are our analyses, Supplement Table 9). The October 17 MIs studied here have sulfur concentrations $(600-2,500 \mathrm{ppm})$ that fall within the ranges in the other studies (and are similar to those in Berlo et al. 2012), and show a systematic, monotonic decline with increasing $\mathrm{SiO}_{2}$. $\mathrm{Cl}$ is comparable in all the studies, with most MIs varying from $\sim 1,000$ to $1,500 \mathrm{ppm} \mathrm{Cl}$ (Fig. 6d). As an aside, the range in $\mathrm{SiO}_{2}$ (50-60 wt\%, anhydrous; Fig. 6b) and host Fo (72-77) does not change in the MI populations studied over the course of the eruption, unlike the bulk ashes, which become markedly more mafic with time (from 4 to $8 \mathrm{wt} \%$ $\mathrm{MgO}$; Rose et al. 1978). This points again to excess crystals within the bulk ashes, specifically an increase in modal olivine (which is observed from 3.6 to 12.6 vol\%; Rose et al. 1978) and not a significant increase in the basaltic component feeding the system. The variation in the 1974 Fuego data from the various studies does not affect the conclusions here, which are based on the variations within our dataset alone.

Within the October 17 dataset reported here, different volatile species vary in a way expected for magma degassing. In most arc magmas, the volatile species degas in the order $\mathrm{CO}_{2}, \mathrm{~S}, \mathrm{H}_{2} \mathrm{O}, \mathrm{Cl}$, and $\mathrm{F}$, reflecting their increasing solubilities in mafic melts (Metrich and Wallace 2008). As magmas rise and decompress, they degas (Newman and Lowenstern 2002), and if they degas significant $\mathrm{H}_{2} \mathrm{O}$, they also crystallize due to the strong effect of $\mathrm{H}_{2} \mathrm{O}$ on the liquidus temperatures of silicates (Blundy and Cashman 2005). Thus, degassing-driven crystallization may lead to coupled variations between $\mathrm{SiO}_{2}$, which increases during crystallization, and $\mathrm{H}_{2} \mathrm{O}, \mathrm{S}$, and $\mathrm{CO}_{2}$, which strongly enter the vapor phase (Blundy and Cashman 2005). This predicted variation is clearly expressed in the October 17 MIs (Fig. 6a, b, c). The relative variations (i.e., larger drop in $\mathrm{CO}_{2}$ than $\mathrm{S}$ and $\mathrm{H}_{2} \mathrm{O}$ ) are also consistent with their relative solubilities. $\mathrm{Cl}$ actually increases with crystallization due to its much higher solubility in the melt (Fig. 6d). In fact, neither $\mathrm{Cl}$ nor $\mathrm{F}$ degases substantially, and maintains a nearly constant ratio of $\mathrm{Cl} / \mathrm{F}=2.89 \pm 8.5 \%$, 

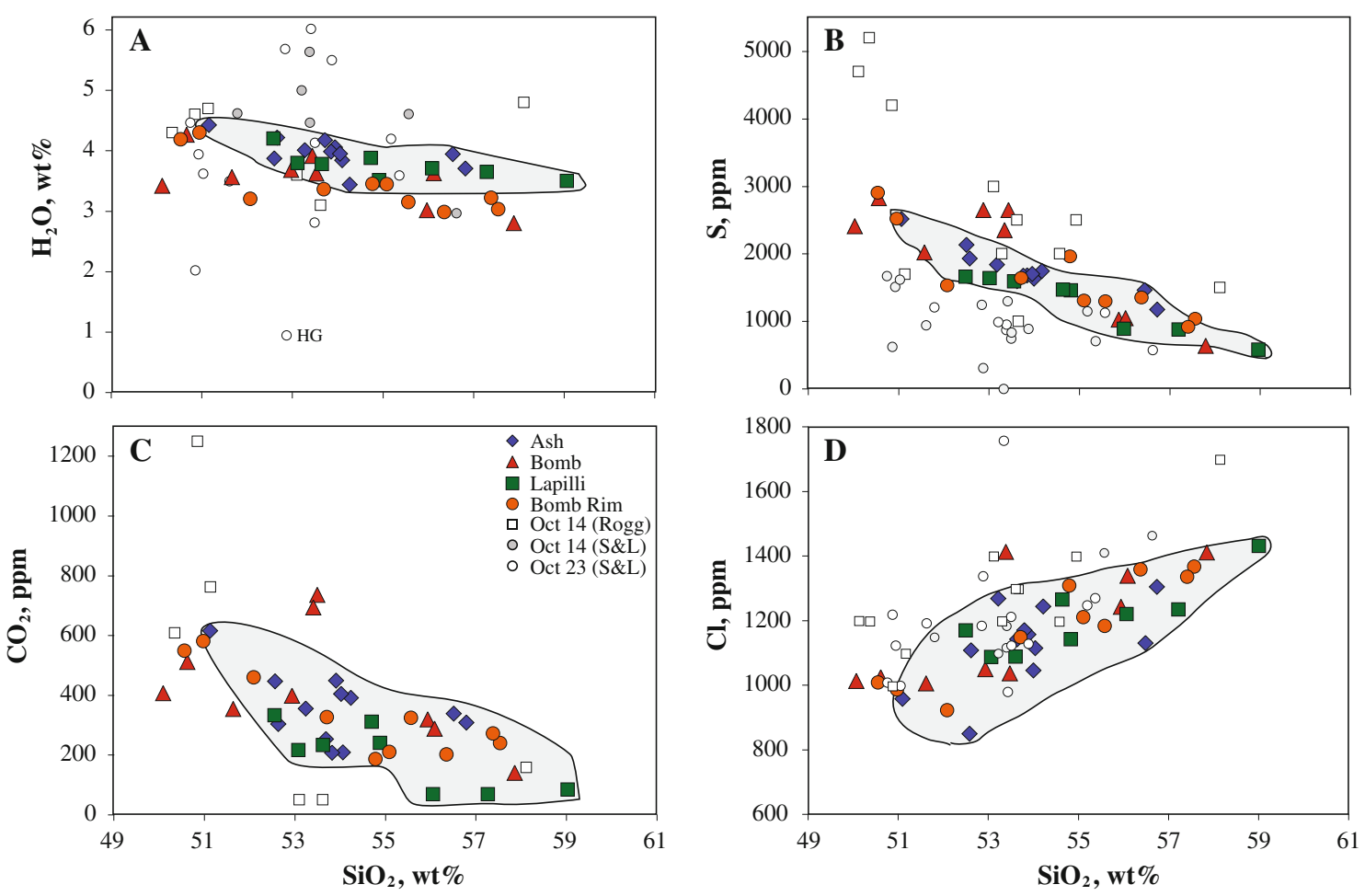

Fig. 6 Variation in volatile species versus $\mathrm{SiO}_{2}$ in melt inclusions from this study and previously published data from Roggensack 2001a (Rogg) and Sisson and Layne 1993 (S\&L). The reported $\mathrm{SiO}_{2}$

is plotted anhydrous. The gray field encloses ash and lapilli MI from this study. The HG label denotes an hourglass inclusion

consistent again with a similar parental magma source for all the MIs.

The MIs from the ash, lapilli, and bomb inclusions show subtle differences in their volatile contents. The lapilli samples contain the most degassed and evolved MI, while the bomb samples contain the most mafic inclusions with least-degassed $\mathrm{S}$ and $\mathrm{CO}_{2}$. On the other hand, all clast sizes contain inclusions that span most of the variation in $\mathrm{SiO}_{2}-\mathrm{S}$ (for example, Fig. 6b), and we suspect if we had a greater sample set, the inclusion populations would be very similar. On the other hand, the bomb and rim MIs have systematically lower $\mathrm{H}_{2} \mathrm{O}$ (up to $1 \mathrm{wt} \%$ ) for the same $\mathrm{SiO}_{2}$ content as the other MIs (Fig. 6a). Most of the inclusions with $\geq 4 \mathrm{wt} \% \mathrm{H}_{2} \mathrm{O}$ derive from the ash samples. This subtle but systematic shift in $\mathrm{H}_{2} \mathrm{O}$ in clasts with different cooling rate is the signal we will explore further below.

\section{Discussion}

Quantifying the extent of water re-equilibration

Here, we consider the extent to which the melt inclusions in the bomb samples have lost $\mathrm{H}_{2} \mathrm{O}$ relative to the more rapidly cooled samples, and whether this loss is consistent with diffusion through the host olivine during post-eruptive cooling. This signal is only observed in $\mathrm{H}_{2} \mathrm{O}$ (Fig. 6a, b, c, d), which is the only volatile species expected to diffuse through olivine on the short timescale of bomb cooling (minutes). The simplest way to quantify $\mathrm{H}_{2} \mathrm{O}$ loss might be to subtract each $\mathrm{H}_{2} \mathrm{O}$ measurement from the maximum concentration $(4.35 \mathrm{wt} \%)$, but this does not take into account the systematic degassing and crystallization trends that affect all volatile concentrations (Fig. 6a, b, c). Our goal is to identify a component of diffusive loss of $\mathrm{H}_{2} \mathrm{O}$ that is independent of the magmatic degassing component. Thus, we have coupled $\mathrm{H}_{2} \mathrm{O}$ with the non-diffusing (over the considered timescales) and incompatible major element $\mathrm{K}_{2} \mathrm{O}$. Like $\mathrm{SiO}_{2}, \mathrm{~K}_{2} \mathrm{O}$ concentrations in melt inclusions largely reflect the extent of crystallization that has occurred prior to trapping (Fig. $4 \mathrm{c}$ ). $\mathrm{K}_{2} \mathrm{O}$ is simpler to interpret than $\mathrm{SiO}_{2}$, however, being highly incompatible in both crystals (the primary observed phenocryst phases in Fuego 1974: olivine, plagioclase, clinopyroxene and magnetite) and vapor, and so its abundance is related to $1 / \mathrm{F}$, or the melt fraction (Roggensack 2001b; Johnson et al. 2008). The factor of 2 observed in $\mathrm{K}_{2} \mathrm{O}$ (and many of the other trace elements, Fig. 5) is consistent with $50 \%$ crystallization linking the most mafic $\mathrm{MI}$ ( $48 \% \mathrm{SiO}_{2}$, hydrous) to the most felsic $\left(58 \% \mathrm{SiO}_{2}\right)$. Ascent-driven crystallization will 
Fig. $7 \mathrm{H}_{2} \mathrm{O}-\mathrm{K}_{2} \mathrm{O}$ variation in melt inclusions from this study. The degassing and crystal fractionation model was calculated using Petrolog3 (Danyushevsky and Plechov 2011) for a magma with a starting composition of $0.50 \mathrm{wt} \% \mathrm{~K}_{2} \mathrm{O}$ and $4.45 \mathrm{wt} \%$ $\mathrm{H}_{2} \mathrm{O}, P_{O}=2.5 \mathrm{kbar}$, $P_{f}=1.1 \mathrm{kbar}, T_{O}=1,030{ }^{\circ} \mathrm{C}$, and decompressing at 30 bars/ ${ }^{\circ} \mathrm{C}$. Dashed contours represent varying degrees of reequilibration. The numbers in italics adjacent to the symbols are $\mathrm{MI}$ radius measurements. Note $0.5-1.0 \mathrm{wt} \% \mathrm{H}_{2} \mathrm{O}$ shift in melt inclusions sampled from ash versus bombs

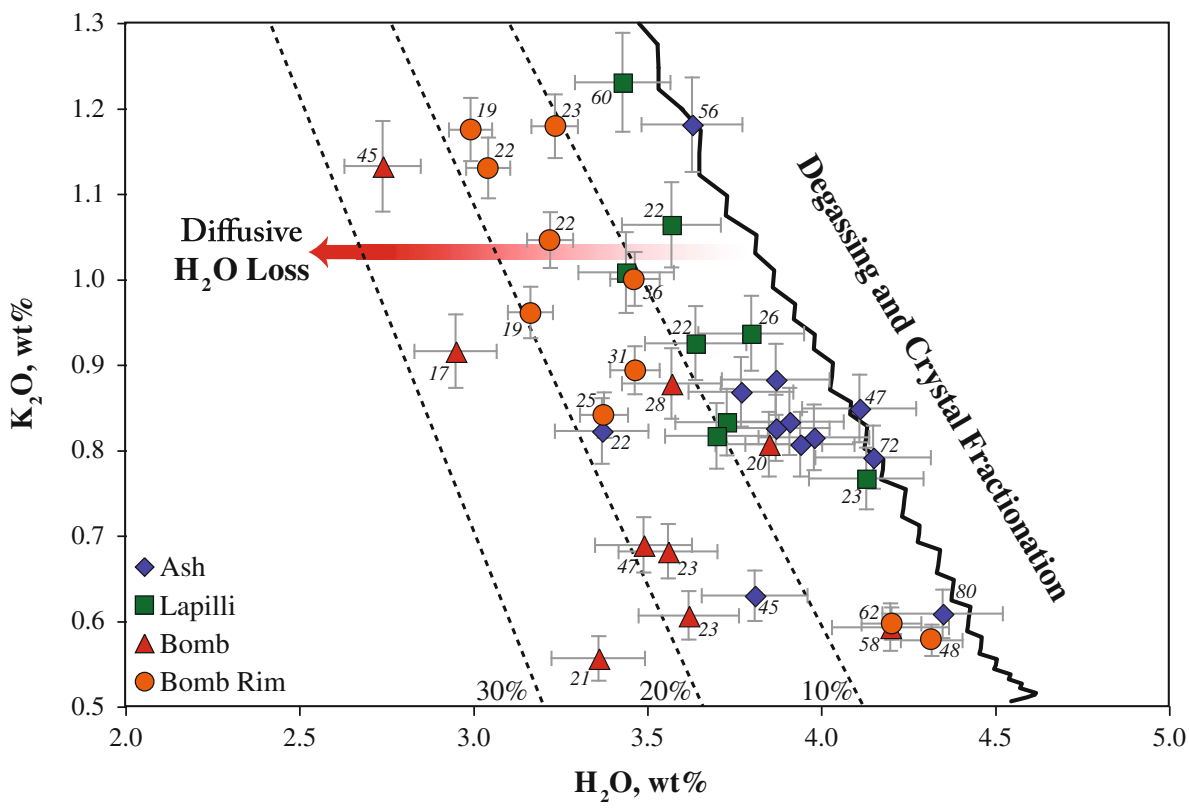

lead to an inverse relationship between $\mathrm{K}_{2} \mathrm{O}$ and $\mathrm{H}_{2} \mathrm{O}$, as is observed in the MIs from the ash and lapilli samples (Fig. 7), and for other phases of the eruption (Sisson and Layne 1993). However, for the same range in $\mathrm{K}_{2} \mathrm{O}$, MIs from bombs demark their own trend shifted by up to $1 \mathrm{wt} \%$ lower $\mathrm{H}_{2} \mathrm{O}$ on average (Fig. 7).

In order to test this interpretation, as well as provide a more quantitative model against which to define $\mathrm{H}_{2} \mathrm{O}$ loss, we fit a polybaric liquid line of descent (LLD) through the ash and lapilli MIs using the software tool Petrolog (Danyushevsky and Plechov 2011). Petrolog3 predicts phase compositions and proportions during crystallization, using statements of mineral-melt equilibrium for major and trace elements. We set the initial pressure to $2.5 \mathrm{kbar}$, based on mixed-vapor saturation pressure of the highest $\mathrm{H}_{2} \mathrm{O}-\mathrm{CO}_{2}$ inclusions (using VolatileCalc; Newman and Lowenstern 2002; Fig. 8b). We set $\mathrm{fO}_{2}$ at the QFM buffer, guided by the $\mathrm{S}$ in the October 17 melt (as discussed above). The four observed phases were $100 \%$ fractionally crystallized during the model run, using the mineral-melt models of Danyushevkey (2001) for olivine, plagioclase, and clinopyroxene, and the model of Ariskin and Barmina (1999) for magnetite. The silicate mineral models include $\mathrm{P}$ and $\mathrm{H}_{2} \mathrm{O}$ dependencies, while the magnetite model does not. The initial starting composition was set to $0.50 \mathrm{wt} \%$ $\mathrm{K}_{2} \mathrm{O}$ and $4.45 \mathrm{wt} \% \mathrm{H}_{2} \mathrm{O}$, and the rest of the major elements were taken from the most primitive PEC-corrected MI composition (137B-5; Table 2).

The best-fit model through the least-degassed ash MIs follows a $\mathrm{P} / \mathrm{T}$ path of $30 \mathrm{bars} /{ }^{\circ} \mathrm{C}$, which is $\mathrm{H}_{2} \mathrm{O}$ saturated over most of the descent. Olivine is on the liquidus at $1,030^{\circ} \mathrm{C}$ and $2.5 \mathrm{kbar}$, and plagioclase + magnetite + cpx join at $\sim 1,005{ }^{\circ} \mathrm{C}$ and 1.7 kbar, where $\mathrm{H}_{2} \mathrm{O}$ saturates. At $1.1 \mathrm{kbar}$ (the minimum pressure recorded by the melt inclusions; Fig. 8b) and $985^{\circ} \mathrm{C}$, the magma is $50 \%$ crystallized, reproducing the twofold $\mathrm{K}_{2} \mathrm{O}$ enrichment, while the $\mathrm{H}_{2} \mathrm{O}$ content has dropped to $3.8 \mathrm{wt} \%$. The zigzag liquid line of descent generated by Petrolog3 derives from the isobaric steps in the simulation; we approximate the trend with a linear parameterization $\left(\mathrm{K}_{2} \mathrm{O}=-0.713\left(\mathrm{H}_{2} \mathrm{O}\right)+3.689, R^{2}=0.993\right)$. For a given concentration of $\mathrm{K}_{2} \mathrm{O}$ in the MIs, this equation provides the $\mathrm{H}_{2} \mathrm{O}$ content in the magma prior to any subsequent diffusive re-equilibration during cooling. Because water loss is relative to the initial and final amount of water, we used the standard form of expressing the degree of re-equilibration: [(predicted $\mathrm{H}_{2} \mathrm{O}-$ measured $\mathrm{H}_{2} \mathrm{O}$ )/(predicted $\mathrm{H}_{2} \mathrm{O}-$ matrix $\mathrm{H}_{2} \mathrm{O}$ ), using $0.06 \mathrm{wt} \% \mathrm{H}_{2} \mathrm{O}$ for matrix glass, based on a SIMS analysis of volcanic glass adhering to an olivine phenocryst from ash sample 127-10, Supplement Table 7]. Although we have interpreted the $\mathrm{H}_{2} \mathrm{O}-\mathrm{K}_{2} \mathrm{O}$ trend in the ash samples as a decompression-driven liquid line of descent, we cannot rule out that some of the trend is produced instead by magma mixing. The actual origin of the trend, however, is less important than the deviations of $\mathrm{H}_{2} \mathrm{O}$ from it.

The degree of re-equilibration for the ash MIs ranges from 0.0 to $18.7 \%$ with an average of $5.4 \%$. Two outliers, 127-6 and 131-3, are responsible for the range and elevated average; excluding these two values, the average reequilibration for the ash MIs is $3.3 \%$, which is within the uncertainty of the SIMS measurement. MIs from lapilli show a range in re-equilibration from 1.7 to $10.9 \%$ with an average of $6.7 \%$. MIs from the bomb rims show a range in re-equilibration from 3.7 to $19.9 \%$ with an average of $13.5 \%$. The MIs from the bombs record the highest extent 


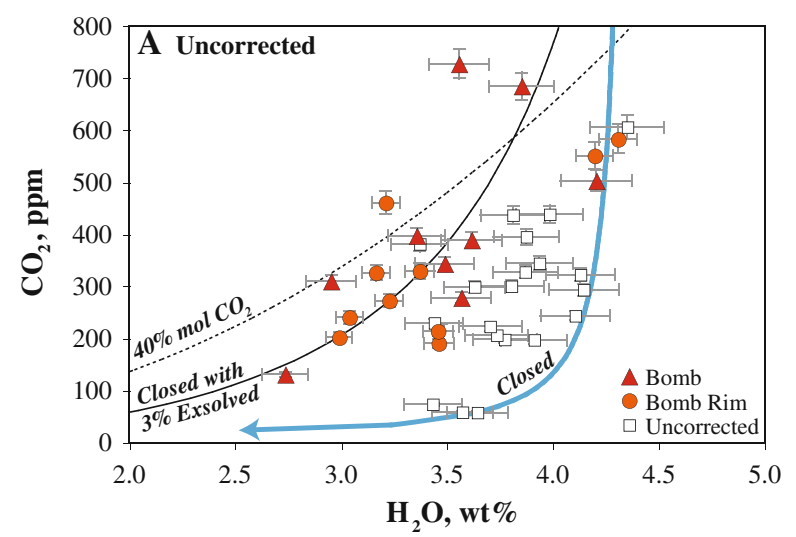

Fig. $8 \mathrm{H}_{2} \mathrm{O}$ versus $\mathrm{CO}_{2}$ in melt inclusions from this study: a uncorrected and $\mathbf{b}$ corrected for inferred diffusive $\mathrm{H}_{2} \mathrm{O}$ loss. In a bomb and bomb rim samples are highlighted in red and orange, respectively; ash and lapilli samples are open squares. Error bars are the SIMS errors reported in the text. The curves are calculated from VolatileCalc (Newman and Lowenstern 2002) for an initial temperature of $1,030{ }^{\circ} \mathrm{C}$ and initial volatile concentrations of $4.3 \mathrm{H}_{2} \mathrm{O} \mathrm{wt} \%$ and $1,250 \mathrm{CO}_{2} \mathrm{ppm}$, the highest reported $\mathrm{CO}_{2}$ concentrations for 1974 Fuego (Roggensack 2001a). The dashed line represents a constant vapor composition isopleth of $40 \mathrm{~mol} \% \quad \mathrm{CO}_{2}$ : $60 \mathrm{~mol} \% \mathrm{H}_{2} \mathrm{O}$. Samples will lie along this line if equilibrated with a fluxing gas of

of re-equilibration, from 5.9 to $26.8 \%$ with an average of $17.9 \%$. These results are consistent with a slower cooling rate predicted for bombs, resulting in greater loss of $\mathrm{H}_{2} \mathrm{O}$ (up to almost $30 \%$; Fig. 7), as well as greater postentrapment crystallization (up to $10 \%$; Fig. 2). We were surprised that the re-equilibration results for the bomb rim MIs were so similar to those for the bomb interior. This is not as expected for a cooling-rate control, as the rim of the bomb should cool more rapidly, and so record less reequilibration, than the bomb core. We will explore the implications of this result below.

\section{Implications for degassing models}

Here, we assess the effect of $\mathrm{H}_{2} \mathrm{O}$ loss, and its restoration, with respect to other volatiles $\left(\mathrm{CO}_{2}\right.$ and $\left.\mathrm{S}\right)$ commonly used to constrain magmatic degassing history. If magma ascends with melt and exsolved bubbles remaining in equilibrium, then closed-system degassing predicts a steep decline in $\mathrm{CO}_{2}$ with little change in $\mathrm{H}_{2} \mathrm{O}$ until the pressure approaches that of pure- $\mathrm{H}_{2} \mathrm{O}$ saturation, after which $\mathrm{H}_{2} \mathrm{O}$ rapidly decreases (Anderson 1989; Newman and Lowenstern 2002; Fig. 8). Despite this simple prediction for ascending magma, few mafic melt inclusion suites show such an $\mathrm{H}_{2} \mathrm{O}-\mathrm{CO}_{2}$ relationship (Metrich and Wallace 2008). Instead, the data are usually scattered, with $\mathrm{H}_{2} \mathrm{O}$ contents less than and/or $\mathrm{CO}_{2}$ higher than those predicted from closed-system degassing. A great deal of effort has gone into explaining such data, involving more complex degassing scenarios such as excess exsolved vapor

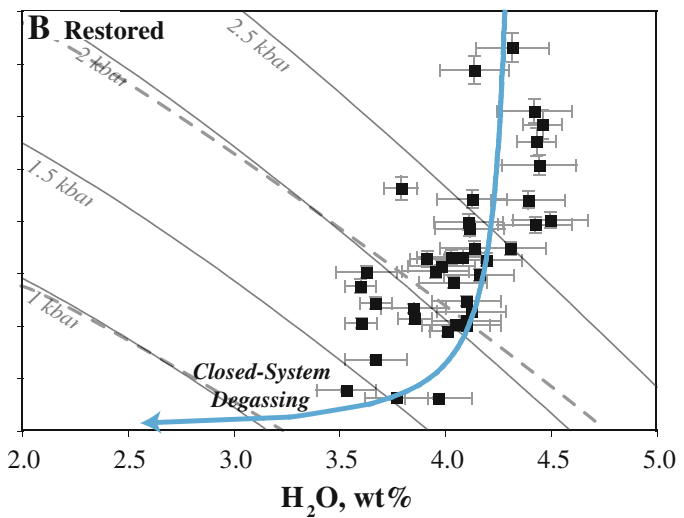

this composition. The solid line shows a closed-system degassing path with $3 \%$ exsolved vapor initially present that is continuously equilibrating. Such excess vapor would have to derive from deeper in the system. The blue closed-system curve starts with no initial vapor, and degasses only vapor that is generated within the magma during decompression. In $\mathbf{b}$, all melt inclusions are corrected following the $\mathrm{K}_{2} \mathrm{O}$ procedure in Fig. 7 and now conform to closedsystem degassing. Isobars were calculated from the previously stated conditions. Solid isobars were calculated using VolatileCalc (Newman and Lowenstern 2002) and dashed isobars from Solex (Witham et al. 2011)

(Anderson 1989), $\mathrm{CO}_{2}$ gas fluxing (Blundy et al. 2010), magma mixing (Dixon et al. 1991), convective mixing (Witham 2011), and diffusive disequilibrium (Gonnermann and Manga 2005). The uncorrected October 17 MIs also show scatter in $\mathrm{H}_{2} \mathrm{O}-\mathrm{CO}_{2}$ (Fig. 8a), with the MIs from the bomb and bomb rim samples plotting furthest from the closed-system degassing line. This could be taken to mean that the bomb and bomb rim MIs have experienced a different degassing history than the other MIs, but there is little evidence for this in the similar $\mathrm{SiO}_{2}-\mathrm{S}$ trend for all the October 17 MIs (Fig. 6b). Instead, it is more likely that $\mathrm{H}_{2} \mathrm{O}$ was systematically lost from these inclusions that experienced a slower cooling rate. Indeed, if the October 17 MIs are corrected for the $\mathrm{H}_{2} \mathrm{O}$ loss, using the $\mathrm{K}_{2} \mathrm{O}$ model above, then they collapse to an $\mathrm{H}_{2} \mathrm{O}-\mathrm{CO}_{2}$ array that is fit reasonably well by simple closed-system degassing (Fig. 8b). Thus, in this case, a simple degassing history is revealed only after correction of diffusive $\mathrm{H}_{2} \mathrm{O}$ loss. This exercise motivates re-examination of previously published MI data. While there is certainly strong, independent evidence for $\mathrm{CO}_{2}$ fluxing in some volcanic systems (Metrich et al. 2004; Spilliaert et al. 2006; Blundy et al. 2010), low$\mathrm{H}_{2} \mathrm{O}$ contents reported in MIs derived from bomb or, worse, lava samples (e.g., Collins et al. 2009; Portnyagin et al. 2007; Sisson and Bronto 1998) more likely reflect some degree of diffusive $\mathrm{H}_{2} \mathrm{O}$ loss, rather than complex degassing processes or unusually dry magma sources.

We can perform a similar analysis for $\mathrm{H}_{2} \mathrm{O}-\mathrm{S}$. Degassing of sulfur is complex due to multiple melt and gas species which vary as a function of $f \mathrm{O}_{2}$ and $f \mathrm{~S}_{2}$ (Wallace 


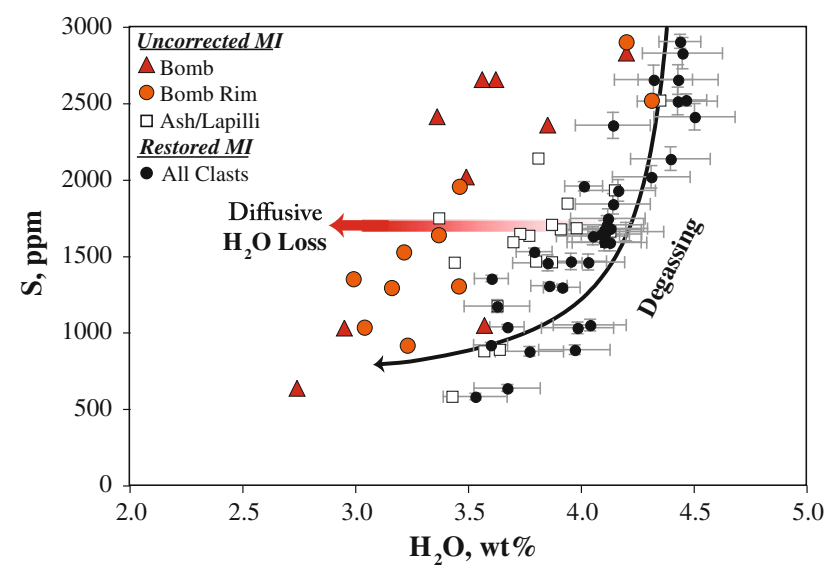

Fig. $9 \mathrm{H}_{2} \mathrm{O}$ versus sulfur variation in melt inclusions from this study highlighting the effect of correction for $\mathrm{H}_{2} \mathrm{O}$ loss. The open squares represent uncorrected ash and lapilli MIs. Similar to Fig. 7 and 8, bomb and rim MIs are shifted approximately $1 \mathrm{wt} \% \mathrm{H}_{2} \mathrm{O}$ at constant sulfur. Once MIs are restored following the method outlined in Fig. 7 , a single bulk partition coefficient for sulfur can be estimated following the methods of Sisson and Layne 1993. The solid line shows a batch fractionation model for simultaneous $\mathrm{H}_{2} \mathrm{O}$ and $\mathrm{S}$ equilibrium degassing with the following parameters: $\mathrm{H}_{2} \mathrm{O}_{\text {initial }}=$ $4.4 \mathrm{wt} \%, S_{\text {initial }}=3,000 \mathrm{ppm}, K d_{S}^{\text {vap } / \text { liq }}=100$, and $\mathrm{H}_{2} \mathrm{O}$ is $5.1 \%$ of the non-liquid separating assemblage (e.g., crystals and vapor)

and Carmichael 1994; Metrich et al. 2009). Nonetheless, melt inclusion suites typically show $\mathrm{H}_{2} \mathrm{O}$ and $\mathrm{S}$ decreasing together, albeit with very different slopes. From this kind of information, a bulk partition coefficient for sulfur $\left(\mathrm{Kd}_{\mathrm{S}}^{\mathrm{vap} / \mathrm{liq}}\right)$ can be determined from an empirical fit to the MI data, assuming mass balance and pure $\mathrm{H}_{2} \mathrm{O}$ vapor (as in Sisson and Layne 1993; Spilliaert et al. 2006; and Johnson et al. 2010). From this approach, however, very different $\mathrm{Kd}_{\mathrm{S}}^{\text {vap/liq }}$ values have been published for different volcanoes, from 1-30 for Mexican volcanoes (Johnson et al. 2010) to 0-60 for Etna (Spilliaert et al. 2006) to 35-110 for Central American volcanoes (Sisson and Layne 1993; Wade et al. 2006; Benjamin et al. 2007). Higher $\mathrm{Kd}_{\mathrm{S}}^{\mathrm{vap} / \text { liq }}$ reflect steeper $\mathrm{S}$ degassing trends with respect to $\mathrm{H}_{2} \mathrm{O}$.

The uncorrected data for October 17 MIs again initially show scatter in $\mathrm{H}_{2} \mathrm{O}-\mathrm{S}$, with the bomb and bomb rim MIs falling systematically to lower $\mathrm{H}_{2} \mathrm{O}$ for their measured $\mathrm{S}$ (Fig. 9). It would be difficult to use these data to constrain $\mathrm{Kd}_{\mathrm{S}}^{\text {vap/liq }}$. However, when the October $17 \mathrm{MIs}$ are restored for $\mathrm{H}_{2} \mathrm{O}$ loss using the $\mathrm{K}_{2} \mathrm{O}$ model (Fig. 7), they form a coherent and very steep $\mathrm{S}$ degassing trend, where $\mathrm{S}$ decreases from almost 3,000 ppm to $500 \mathrm{ppm} \mathrm{S}$ while $\mathrm{H}_{2} \mathrm{O}$ varies from 4.5 to $3.5 \mathrm{wt} \%$. This translates into a high $\mathrm{Kd}_{\mathrm{S}}^{\text {vap/liq }}$ of 100 for the degassing path, like the other Central American volcano $\operatorname{Irazú}\left(\mathrm{Kd}_{\mathrm{S}}^{\text {vap/liq }}=110\right)$, but unlike Sisson and Layne's (1993) calculation for other days of the 1974 eruption $\left(\mathrm{Kd}_{\mathrm{S}}^{\text {vap/liq }}=34\right)$. The difference clearly derives from both the lower $\mathrm{S}$ concentrations (mostly $<1,500$ ppm) and higher spread of $\mathrm{H}_{2} \mathrm{O}$ (Fig. 6a) in Sisson and Layne's study, from values $>4.5 \mathrm{wt} \% \mathrm{H}_{2} \mathrm{O}$ not found in this study or Roggensack's (2001a), to values $<2 \mathrm{wt} \%$, which are mostly for hourglass inclusions that are connected to the exterior degassing melt, and so have likely suffered diffusive loss of $\mathrm{H}_{2} \mathrm{O}$. Our October $17 \mathrm{MI}$ trend is also very different from most of the Mexican MI suites (Johnson et al. 2010), which show limited variation in $\mathrm{S}$ ( \pm 100 's ppm) and large variations in $\mathrm{H}_{2} \mathrm{O}$ (several wt\%). This variable degassing of sulfur is likely revealing something important about the different magmatic systems, their $f \mathrm{O}_{2}$, and how they evolve during crystallization and degassing. Some of the $\mathrm{S}$ variation in Fuego MI may be due to a change in $f \mathrm{O}_{2}$ during degassing and crystallization, which affects the sulfur concentration at sulfide saturation (Jugo et al. 2010). There is some evidence for this in the increase in $\mathrm{K}_{\mathrm{d}}\left(\mathrm{V}_{\mathrm{o} / / \text { liq }}\right)$ during magma evolution discussed above (Supplement Table 6). But a prerequisite to understanding sulfur degassing is better control on $\mathrm{H}_{2} \mathrm{O}$ and how much of its variation may be due to diffusive loss versus degassing.

Melt inclusion size dependence for diffusive loss of $\mathrm{H}_{2} \mathrm{O}$

One test of a diffusive mechanism is a relationship to the relevant length scale. With all other variables being constant, MIs that are small and close to the crystal rim should experience the most diffusive re-equilibration for a given timescale. Qin et al. (1992) demonstrated that MI reequilibration will depend not only on the diffusivity $(D)$ and partition coefficient $\left(K_{d}\right)$ in the crystal host, but also the size of the inclusion and distance to the crystal rim. Assuming a fixed MI radius, the time required for MI reequilibration increases with a larger host crystal radius. For a constant host crystal radius, a smaller MI will re-equilibrate more rapidly than a larger MI. This oversimplification does not hold true when the ratio of the MI to host crystal radius approaches 0.7 (Qin et al. 1992), but this condition is far from that observed in the Fuego MI population, where the ratio is $<0.23$.

In Fig. 10, we have plotted the re-equilibration of each MI as a function of its radius. Regardless of the clast from which the MIs originated, the analyzed MIs show the predicted relationship where the larger inclusions have reequilibrated less than the smaller ones. Most of the inclusions that have re-equilibrated more than $15 \%$ have a radius of $<30 \mu \mathrm{m}$ regardless of the clast size (Fig. 10). The one exception is a bomb MI of $46 \mu \mathrm{m}$ radius, which is closer to the glassy rim of the crystal $(66 \mu \mathrm{m})$ than any other bomb MI, consistent with more extensive re-equilibration. This is in contrast to the MIs in bomb samples 134D-9 (26 $\mu \mathrm{m}$ radius) and 137B-17 $(19 \mu \mathrm{m})$, which have 


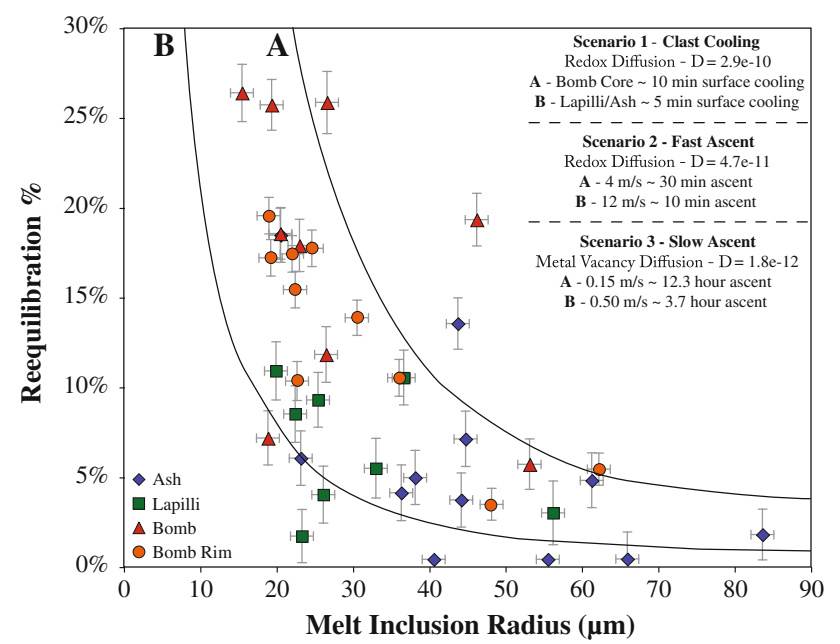

Fig. 10 Melt inclusion radius versus percent re-equilibration from MIs in this study. $\mathrm{Y}$-axis error bars include both $\mathrm{K}_{2} \mathrm{O}$ and $\mathrm{H}_{2} \mathrm{O}$ errors propagated through the re-equilibration function. $\mathrm{X}$-axis error bars represent the average difference between the measured MI radii and that approximated from a spherical radius of a melt inclusion ellipsoid. Diffusivities (D) are calculated at $1,030{ }^{\circ} \mathrm{C}$, using an Arrhenius function and $D_{o}$ and $\mathrm{E}$ as in the text. Model curves $A$ and $B$ were calculated using an adaptation of the MI re-equilibration equations in Qin et al. (1992), discretized to allow variations in D (linking its temperature-dependence to the clast cooling rate) and $\mathrm{H}_{2} \mathrm{O}$ outside the MI host (linking it to the ascent rate). Bomb and bomb rim samples tend to record higher degrees of re-equilibration than lapilli and ash for similar sized MIs (most clear for MIs between 15 and $25 \mu \mathrm{m}$ ), consistent with varying post-eruptive cooling rates (Scenario 1) or magma ascent rates (Scenario 2 and 3). Scenario 1 considers constant external $\mathrm{H}_{2} \mathrm{O}$ with changing temperature to determine reequilibration during post-eruptive cooling, whereas, Scenario 2 and 3 consider constant temperature and varying external $\mathrm{H}_{2} \mathrm{O}$ to determine re-equilibration during ascent only

experienced less re-equilibration than expected, due to being the greatest distance from the rim and being adjacent to a large melt embayment, respectively. Thus, there is some effect of rim distance as well, as predicted, but we do not find a relationship in the population as a whole as we do for MI size. This is possibly because there is significantly more ambiguity in the measured distance to a rim than the measurement of the size of the MI. When preparing MIs for analysis, the goal is to expose the maximum amount of glass as possible, which means that each MI radius measurement is the maximum size for that MI. On the other hand, because the MIs can be located at any depth in the host crystal, the final size of the crystal after polishing (when the measurements were taken) might not reflect the actual size of the crystal or the geometry of the MI within it. Additionally, crystals can be broken during crushing to release them from the host matrix, thus the actual crystal size may not be recoverable. Figure 10 also exhibits the sampling bias previously mentioned, where bomb inclusions are typically smaller in size than ash inclusions. For this reason, the end members of the total inclusion population include three small bomb MIs, which have experienced $>25 \%$ re-equilibration, and two large ash MIs, which have experienced $<1 \%$ re-equilibration.

Although there appears to be a strong control on $\mathrm{H}_{2} \mathrm{O}$ diffusive equilibration due to $\mathrm{MI}$ size, there is still a strong difference between the different clast sizes. If only the MIs $<40 \mu \mathrm{m}$ in radius are considered, there is a clear transition between the lapilli MI, which reach a maximum value of $10 \%$ re-equilibration, and the bomb and bomb-rim MIs, which record almost uniformly greater than $10 \%$. For MIs larger than $40 \mu \mathrm{m}$, ash samples tend to show $<5 \%$ reequilibration, whereas MIs from the other clast sizes tend to show greater than $5 \%$. Thus, both MI radius and clast size effects can be observed in our dataset, one controlling a length scale and the other controlling the timescale for diffusive $\mathrm{H}_{2} \mathrm{O}$ loss.

\section{Timescales of clast cooling}

We can test the clast cooling hypothesis by coupling two diffusion problems - thermal (clast cooling) and chemical $\left(\mathrm{H}_{2} \mathrm{O}\right.$ diffusion in olivine). The question is whether a $\sim 50 \mu \mathrm{m}$-diameter inclusion can lose $25-30 \%$ of its water through a $\sim 600-\mu \mathrm{m}$ olivine in the time it takes $(10 \mathrm{~min})$ a $6-\mathrm{cm}$ clast to cool (these values are representative of the most re-equilibrated bomb MIs in Table 2). The first step in answering this question requires calculating the duration of cooling for clasts of different sizes (we used an online tool to solve for 1-D heat conduction in a convectively cooled sphere; Recktenwald 2006). The input variables include a thermal conductivity of $0.024 \mathrm{~W} \mathrm{~K}^{-1} \mathrm{~m}^{-1}$ (Stroberg et al. 2010), thermal diffusivity of $3.3 \times 10^{-7} \mathrm{~m}^{2} \mathrm{~s}^{-1}$ (Hort and Gardner 2000), and a heat transfer coefficient of $120 \mathrm{~W} \mathrm{~m}^{-2} \mathrm{~K}^{-1}$ (Stroberg et al. 2010), appropriate for mafic scoria. The initial temperature was set at $1,030{ }^{\circ} \mathrm{C}$ (from the Petrolog3 LLD calculation), and the ambient temperature surrounding the pyroclast was set at $30^{\circ} \mathrm{C}$.

The model was run for pyroclasts with three different radii, $0.1 \mathrm{~cm}, 1.0 \mathrm{~cm}$, and $3.0 \mathrm{~cm}$, representing the ash, lapilli, and bomb, respectively. Figure 11 illustrates the temperature-time paths experienced inside the lapillus and bomb. From a purely conductive cooling perspective, an olivine phenocryst in ash takes less than one second to cool from $1,030{ }^{\circ} \mathrm{C}$ to $450{ }^{\circ} \mathrm{C}$. The core of a single $2-\mathrm{cm}$ (diameter) lapillus takes about $60 \mathrm{~s}$ to cool, while a $6-\mathrm{cm}$ (diameter) bomb takes $10 \mathrm{~min}$, over the same temperature range. These are maximum (core) cooling times (minimum cooling rates), as MIs closer to the clast edges will cool more rapidly. Other factors may further increase the cooling times, such as co-deposition of hot clasts or comminution in the upper conduit. Likewise, ash (in particular) may remain in the eruptive plume for several minutes, and experience elevated external temperatures as the eruptive 


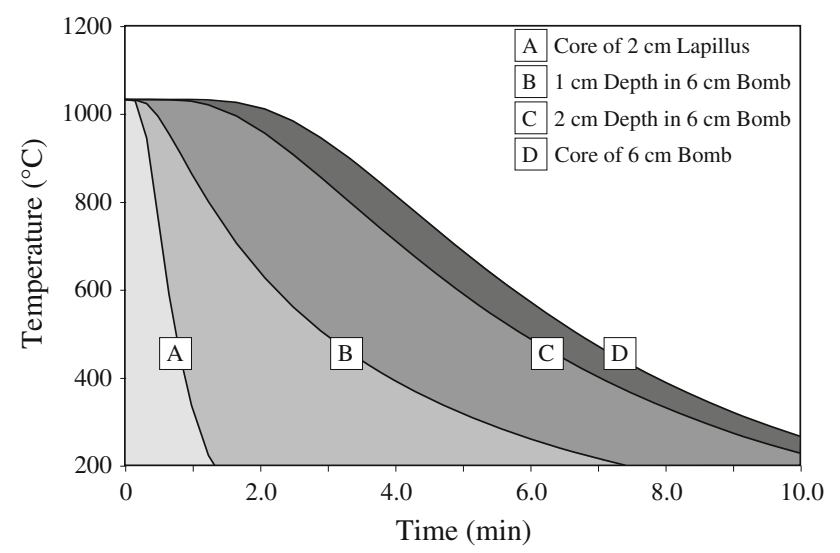

Fig. 11 Conductive cooling paths for various depths in a 6-cmdiameter bomb and a 2-cm-diameter lapillus, as in this study. See the text for the details of how these lines were calculated. Melt inclusions (MIs) from bombs experience the slowest post-eruptive cooling rate and in this study were sampled from anywhere between lines $C$ and $D$. MIs from the lapillus experience faster post-eruptive cooling rate and were sampled from anywhere between the ordinate axis and line $A$. MIs from the bomb rim experience an intermediate cooling rate (the ordinate axis to line $C$ )

plume cools from magmatic temperatures (Hort and Gardner 2000). To simulate these latter two processes, we repeated the above conductive cooling calculations for other external temperatures $\left(500,300,100{ }^{\circ} \mathrm{C}\right)$. Although they change the overall cooling curves and reduce the average cooling rate for the clast, it proved to be inconsequential because the majority of water loss occurs prior to $700{ }^{\circ} \mathrm{C}$ and the test with elevated external temperatures did not add appreciable time to this diffusion "window".

Next we consider the chemical diffusion of $\mathrm{H}_{2} \mathrm{O}$ through olivine over the same timescale as the conductive cooling of the clast. These processes are linked because temperature, which varies over the cooling interval, strongly affects the diffusivity (D) of any chemical species. While the analytical solutions in Qin et al. (1992) provides a good first-order approximation of the degree of re-equilibration, they are limited to constant diffusivity and an initial stepwise concentration profile with constant element concentrations across the crystal and MI. In order to incorporate time-temperature dependence of the diffusion coefficient $D$ of hydrogen, we solved numerically for element diffusion from a melt inclusion through a host crystal and into a surrounding melt during clast cooling. Using a finite-difference scheme, we discretized the governing Eq. (2) in Qin et al. (1992) for element concentration $C$ :

$$
\begin{aligned}
C_{i+1, j}(x)= & C_{i, j}+D_{i, j} \frac{\Delta t}{(\Delta r)^{2}}\left(C_{i, j+1}-2 C_{i, j}+C_{i, j-1}\right) \\
& +2 D_{i, j} \frac{\Delta t}{x \Delta r}\left(C_{i, j+1}-C_{i, j}\right)
\end{aligned}
$$

with $\Delta r$ and $\Delta t$ being the step size in space and time. The boundary conditions of the crystal at the inner MI boundary $a$ and the outer surrounding melt boundary $b$ were discretized as follows:

$C_{i+1, a}=C_{i, a}+\frac{\Delta t}{\Delta r} \frac{\beta}{a} D_{i, a}\left(C_{i, a+1}-C_{i, a}\right)$

$C_{b}=C_{\text {melt }} k$

where $\beta=3 k \rho_{\text {crystal }} / \rho_{\text {melt }}$ with $K_{d}$ being the partition coefficient of hydrogen between olivine and melt and $\rho_{\text {crystal }}$ and $\rho_{\text {melt }}$ being the crystal and melt densities, respectively. In applying the model, we assumed isotropic diffusivity and a constant partition coefficient $\mathrm{Kd}_{\mathrm{H}_{2} \mathrm{O}}^{\mathrm{O} / \text { liq }}=$ 0.001 (Aubaud et al. 2004; Koga et al. 2003). The timedependent diffusion coefficient is calculated using the temperature evolution of the clast cooling model, and the standard Arrhenius formulation, $D=D_{o} \mathrm{e}^{-E / R T}$, where $\mathrm{E}$ is the activation energy and $\mathrm{R}$ is the gas constant. Because most studies of $\mathrm{H}$ diffusion in olivine predict a similar activation energy, we assumed $E_{a}=130 \mathrm{~kJ} / \mathrm{mol}$ and varied $D_{o}$ within the bounds of experimental determinations (see references to Fig. 12). Outer boundary conditions were set to reflect equilibrium $\mathrm{H}_{2} \mathrm{O}$ concentrations at atmospheric pressure (i.e., $C_{\text {melt }}$ refers to the hydrogen concentration in the matrix melt). The initial concentration was taken to be the highest observed water content in melt inclusions from ash samples $\left(4.4 \mathrm{wt} \% \mathrm{H}_{2} \mathrm{O}\right)$. We validated the numerical diffusion model against the solution of Qin et al. (1992) for constant temperature.

The Qin model has other limitations besides constant diffusion coefficients. The melt inclusion and crystal are both assumed to have a spherical geometry, with the inclusion located in the center of the host. Thus, the relevant diffusive length scale is given as $a / b$, where $a$ is the radius of the inclusion and $b$ is the radius of the crystal. This geometry is obviously idealized, and not typical of natural samples. Off-center melt inclusions close to the crystal rim may equilibrate an order of magnitude faster than predicted by the Qin model, and other inclusions or embayments within the same crystal will inhibit re-equilibration (Ruprecht et al. 2010). Nonetheless, we do not take into account such irregularities here.

In applying the diffusion model, we considered first the upper bound of the data, which is largely defined by the bomb and bomb rim MI, and used the bomb core cooling path in Fig. 11 (Curve A in Fig. 10). This provides a maximum cooling time available for diffusion and fits the data for $D_{o}=5 \times 10^{-5} \mathrm{~m}^{2} / \mathrm{s}$, which translates to a maximum $D$ of $\sim 2.95 \times 10^{-10}$ at $1,000{ }^{\circ} \mathrm{C}$. Such a high diffusivity is permissible, but at the maximum range of what has been measured in the laboratory (see references to Fig. 12). The lower bound of the data, defined largely by 


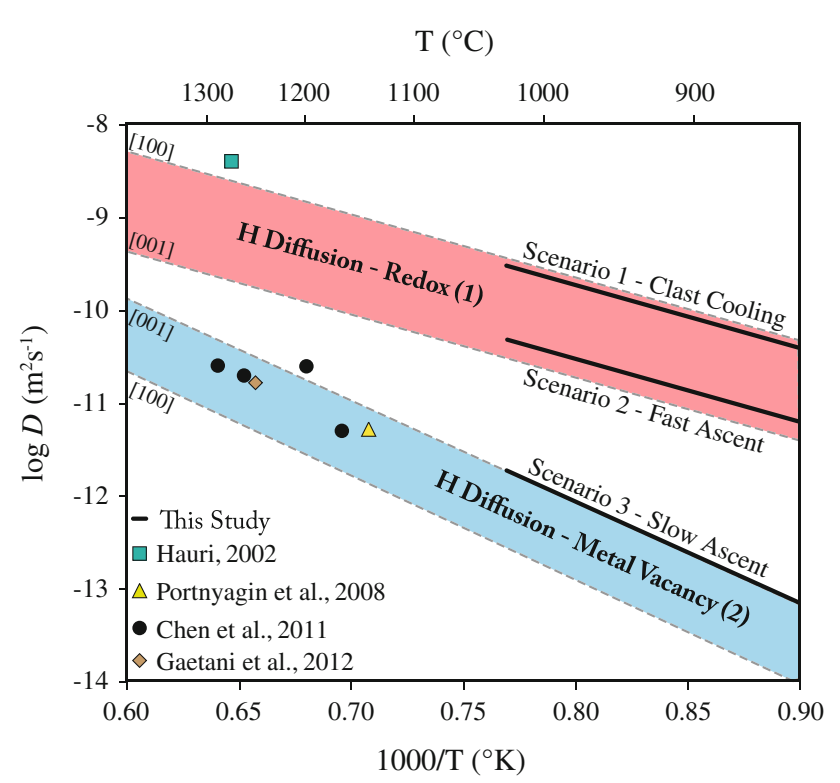

Fig. 12 Arrhenius plot illustrating hydrogen diffusivities in olivine consistent with Fuego melt inclusion cooling and ascent scenarios. Colored regions represent two types of proton diffusion in ironbearing olivines: (1) proton-polaron redox mechanism from Kohlstedt and Mackwell (1998), and (2) metal vacancy mechanism from Demouchey and Mackwell (2006), with diffusion along different crystallographic axes as shown in brackets. Points represent experimentally determined D for olivine-hosted melt inclusions during laboratory heating (Hauri 2002 and Chen et al. 2011) and rehydration (Portnyagin et al. 2008 and Gaetani et al. 2012)

the ash and lapilli MI (Curve B in Fig. 10), can be fit using the same $D_{o}$ and a cooling rate of $100{ }^{\circ} \mathrm{C} / \mathrm{min}$.

While this exercise illustrates that the data are satisfactorily described by a diffusion model with permissible parameters, there are three issues that require us to explore alternatives. The first is that it requires the fastest diffusivities of $\mathrm{H}$ in olivine measured in laboratory studies, equivalent to the fast redox mechanism summarized by Demouchy and Mackwell (2006). We discuss at the end of the paper whether this mechanism is reasonable or not, but we are driven to this extreme because so little time is available for post-eruption diffusion $(<10 \mathrm{~min})$. The second issue is that several of the ash and most of the lapilli MIs have experienced $5 \%$ or more re-equilibration, and yet their expected cooling rates are much faster than the $100{ }^{\circ} \mathrm{C} / \mathrm{min}$ rate required to fit the data (Curve B). There is not really enough post-eruptive cooling time to permit any re-equilibration of the ash MIs. The third issue is that the MIs from the different clast samples do not entirely conform to the expectations for cooling rate alone. There should be a gradual increase in re-equilibration from ash to lapilli to bomb rims to the bomb core, given the longer times for conductive cooling shown in Fig. 10. Instead, we observe that the ash and lapilli MIs overlap and the bomb and bomb-rim MIs overlap. It is possible that we do not have enough resolution to distinguish these populations, given the analytical and modeling assumptions we have made, although our best estimate of the propagated errors $( \pm 3 \%)$ suggests that we do. We thus consider below other scenarios to explain the $\mathrm{H}_{2} \mathrm{O}$ re-equilibration data that may work in concert with post-eruptive clast cooling.

Other possibilities for water loss

One possibility to explain the two groups of MIs (ash/ lapilli and bomb/bomb rim) is that the inclusions trapped in the bombs derive from a drier initial magma than the MIs in the other clasts. This is not supported, however, by the similarity in ratios of trace elements (e.g., Ba/Zr; Fig. 5) and non-degassing volatiles $\left(\mathrm{Cl} / \mathrm{SiO}_{2}\right.$; Fig. $\left.6 \mathrm{~d}\right)$ in all the MIs, which point to a similar parental magma. Moreover, the bomb MI with the least $\mathrm{H}_{2} \mathrm{O}$ re-equilibration and PEC (M-134D-14) has the same $\mathrm{H}_{2} \mathrm{O} / \mathrm{Ce}$ ratio $(\sim 4,000)$ as the ash MI with the highest $\mathrm{H}_{2} \mathrm{O}$ content (M-132-3). $\mathrm{H}_{2} \mathrm{O} / \mathrm{Ce}$ is a source feature from the subduction zone (Plank et al. 2009) that would be expected to vary for parental magmas with different initial water contents or deep degassing histories. Thus, we do not think the melt inclusions in the bomb derive from a parent with lower initial $\mathrm{H}_{2} \mathrm{O}$.

Another possibility is that bomb MI might have reequilibrated during storage in a shallow crustal magma reservoir. This scenario would entail olivine phenocrysts, which have entrapped MIs at depth, ascending to a shallow magma chamber and residing there for some period of time before final ascent to the surface. While at this shallow level, $\mathrm{H}_{2} \mathrm{O}$ concentrations in the MIs will re-equilibrate with the concentration in the surrounding melt (e.g., if at $1 \mathrm{~kb}$, or $\sim 4 \mathrm{~km}$, then $3 \mathrm{wt} \% \mathrm{H}_{2} \mathrm{O}$, based on the vaporsaturation isobars shown in Fig. 8). If all of the stored MIs re-equilibrate at the same storage depth, then MIs would take on a single $\mathrm{H}_{2} \mathrm{O}$ concentration. Experimental evidence (Portnyagin et al. 2008) has shown olivine-hosted MIs are capable of gaining $2.5 \mathrm{wt} \% \mathrm{H}_{2} \mathrm{O}$ in 2 days, so this scenario holds for any storage time greater than a few days. The bomb inclusions, however, do not appear to be reset to a common $\mathrm{H}_{2} \mathrm{O}$ concentration and so do not support this scenario of long-term ( $>2$ days) storage in a shallow magma reservoir.

Previous models have argued for storage of magma at different depths in the Fuego plumbing system (Roggensack 2001a; Berlo et al. 2012), and so perhaps the bomb MIs reflect re-equilibration at different depths. If the bomb MIs derive from vertically stored magma, then MIs will equilibrate to exterior melt that has different $\mathrm{H}_{2} \mathrm{O}$ contents as a function of storage depth if pressures are $<1.5 \mathrm{~kb}$ (i.e., exterior melt has $\mathrm{H}_{2} \mathrm{O}$ contents controlled by the vaporsaturation pressure, see Fig. 8). If this were the case, however, then one would expect the MIs trapped in the 
bomb samples to have more variable $\mathrm{K}_{2} \mathrm{O}-\mathrm{SiO}_{2}$, like the diverse melts that exist in the Fuego plumbing system (Fig. 4d). The strong coherence in $\mathrm{K}_{2} \mathrm{O}$ and $\mathrm{SiO}_{2}$ concentrations of all the October $17 \mathrm{MI}$, including those in the bomb samples (Fig. 4c), provides strong evidence that all the MI were derived from a single magma that fed the eruption, and not melt stored in the plumbing system for any appreciable length of time.

Another possibility is that the bomb MI underwent a different degassing history. This is difficult to accommodate, however, given the coherent $\mathrm{SiO}_{2}-\mathrm{S}$ and $\mathrm{SiO}_{2}-\mathrm{CO}_{2}$ systematics for all the MI (Fig. 6b, c). Only $\mathrm{H}_{2} \mathrm{O}$ behaves differently in the bomb and bomb rim MIs, and this is more consistent with a diffusive than a degassing process, as only $\mathrm{H}_{2} \mathrm{O}$ is expected to diffuse rapidly through olivine. It would also be difficult to explain the greater PEC of the bomb MIs (Fig. 2) with a degassing scenario, since this process occurs after the melt is isolated from the degassing magma.

Other eruptive processes may also have affected fine and coarse pyroclasts differently. The October 17 phase of the Fuego 1974 eruption involved pulsating intense explosions with a 1-min periodicity (Rose et al. 1978). Rose et al. (2008) suggested that the large abundance of the finer pyroclastic material could derive from comminution within the volcanic conduit. The Fuego conduit is perhaps about $10 \mathrm{~m}$ in diameter and could be $1 \mathrm{~km}$ or more in length, measured from the fragmentation level to the summit (Rose, personal communication). During the eruption, pyroclasts form from explosive vesiculation, with particles having a wide range of sizes. Above the fragmentation level in the conduit, there is a vertically directed gas thrust that blows out fines quickly and larger pyroclasts are retained within, especially in between explosions. Large pyroclasts represent harder enclaves of less vesicular and perhaps more crystal-rich magma which resist fragmentation. They bounce off the conduit walls and each other during explosions while the fines (fragmented from highly vesicular and more fragile material) are blown out much more quickly (Dufek et al. 2012). Thus, the big pyroclasts can spend longer within the hot conduit before they become part of the emergent volcanic cloud and fallout. Bombs might only come out during the big explosions, which happened every minute or so, while ash would be blown out continually. With additional time in the upper conduit at high temperatures, this process may be another contribution to the observed water loss in the bomb and bomb rim MIs.

The finite loss of some $\mathrm{H}_{2} \mathrm{O}$ from the ash MI, however, requires another process that promotes $\mathrm{H}_{2} \mathrm{O}$ loss, most likely pre-eruptive ascent deeper in the conduit. The driving force for $\mathrm{H}_{2} \mathrm{O}$ diffusion through olivine starts as soon as the exterior magma degases to lower $\mathrm{H}_{2} \mathrm{O}$ concentration than that trapped in the melt inclusion. This will occur in the magma conduit when the exterior magma begins to degas $\mathrm{H}_{2} \mathrm{O}$, at approximately $\sim 2 \mathrm{~kb}$ (based on the $\mathrm{H}_{2} \mathrm{O}-$ $\mathrm{CO}_{2}$ vapor saturation pressures; Fig. 8b, Table 2) or $1.7 \mathrm{~kb}$ (based on the Petrolog3 LLD), or $\sim 7-8 \mathrm{~km}$ in the crust (assuming a magma density of $2600 \mathrm{~kg} / \mathrm{m}^{3}$ ). This ascent time will drive water loss in all melt inclusions, but may affect more those that end up in bomb-sized fragments. If some portion of the magma ascends more slowly above these depths, for example along the conduit walls, then this would give MIs more time to re-equilibrate to lower $\mathrm{H}_{2} \mathrm{O}$ concentrations, as observed in the bomb and bomb rim MIs. This more slowly ascending magma could have different physical properties (e.g., viscosity and vesicle distribution) that might preferentially lead to a bomb-sized fragment. Microlite- and vesicle-population studies of bomb versus lapilli clasts might be used to test for this scenario by providing information about pre-fragmentation conditions (e.g., Sable et al. 2006; Wright et al. 2007). Alternatively, we can test this ascent scenario by modifying our diffusion model.

\section{Diffusive re-equilibration on ascent}

In this scenario, diffusion of $\mathrm{H}_{2} \mathrm{O}$ out of the $\mathrm{MI}$ is driven by the loss of $\mathrm{H}_{2} \mathrm{O}$ in the external magma during ascent and degassing in the volcanic conduit. In contrast to the clast cooling model, we assume this process is relatively isothermal, consistent with the Petrolog3 model that predicts $<50^{\circ}$ cooling during ascent (30 bars per degree over 1,400 bars). On the other hand, the $\mathrm{H}_{2} \mathrm{O}$ concentration in the external melt changes systematically upon ascent, and this needs to be taken into account in the diffusion model. In this second set of numerical calculations, we solved the diffusion equation (Eq. 1) for a time-dependent boundary condition (Eq. 3), where $C_{\text {melt }}$ changes as the magma ascends. We assume $C_{\text {melt }}$ follows the pure $\mathrm{H}_{2} \mathrm{O}$ saturation curve calculated from Newman and Lowenstern (2002) for mafic melt at $1,030{ }^{\circ} \mathrm{C}$. We set the starting pressure of the model at $1.9 \mathrm{kbar}(7.5 \mathrm{~km})$ based on the saturation depth of the highest $\mathrm{H}_{2} \mathrm{O}$ measured in the Fuego MIs (132-3; $4.35 \mathrm{wt} \% \mathrm{H}_{2} \mathrm{O}$ ) and assumed a constant decompression rate.

The magma ascent rate for basaltic eruptions is an elusive parameter, requiring the use of such diverse observations as microlite crystallization, hornblende rim growth, mass eruption rate, and seismicity (Rutherford 2008). No published estimates exist for the 1974 eruptions of Fuego, although the mass eruption rates have been estimated for the October 14 phase $\left(3 \times 10^{6} \mathrm{~kg} / \mathrm{s}\right.$, Rose et al. 2008). Given assumptions about conduit diameter $(5-50 \mathrm{~m})$ and using a magma density of $2,600 \mathrm{~kg} / \mathrm{m}^{3}$, such a mass eruption rate would require magma ascent rates of $\sim 0.1$ to 
$10 \mathrm{~m} / \mathrm{s}$. This range in ascent rates is consistent with those generally associated with sub-Plinian eruptions (Cashman 2004). Using ascent rates near the upper end of this range, the melt inclusion data can be fit with a constant D roughly one order of magnitude lower than the clast cooling model $\left(D_{o}\right.$ of $8 \times 10^{-6} \mathrm{~m}^{2} / \mathrm{s}$ vs. $5 \times 10^{-5} \mathrm{~m}^{2} / \mathrm{s}$ and $E_{a}=130 \mathrm{~kJ} /$ mol), with bomb magma ascending at $4 \mathrm{~m} / \mathrm{s}$ (curve $A$, slower, along conduit walls) and ash/lapilli magma ascending at $12 \mathrm{~m} / \mathrm{s}$ (curve $\mathrm{B}$, faster, middle of conduit). These ascent rates correspond to total ascent times of 30 and $10 \mathrm{~min}$ respectively. Alternatively, we can fit the data with slower ascent rates that correspond to the slower diffusion mechanism for hydrogen in olivine (accommodated through metal vacancy diffusion; Kohlstedt and Mackwell 1998, Demouchey et al. 2006, Chen et al. 2010). For $D_{\mathrm{o}}$ of $5 \times 10^{-4} \mathrm{~m}^{2} / \mathrm{s}$ (fastest metal vacancy diffusion; Demouchy and Mackwell 2003), the data are fit by an ascent rate of $0.50 \mathrm{~m} / \mathrm{s}$ for the ash/lapilli population, and $0.15 \mathrm{~m} / \mathrm{s}$ for the bomb population, corresponding to ascent times of $\sim 4$ and $12 \mathrm{~h}$, respectively. Constant ascent rates are clearly an oversimplification, and it is instead likely that magmas will accelerate as they ascend. This will lead to a trade-off as magmas spend less and less time in the shallower regions of the conduit where there is the greatest driving force for re-equilibration due to the rapidly decreasing water contents in the exterior magma. The calculated ascent times here are thus probably minima.

Thus, we can fit the melt inclusion data equally well with three scenarios for diffusive water loss (Fig. 11). Scenario 1 is for clast cooling only (discussed above) and assumes no loss during ascent. This requires hydrogen diffusivities equivalent to the fastest measured in olivine $\left(2.9 \times 10^{-10} \mathrm{~m}^{2} / \mathrm{s}\right.$ at $\left.1,030{ }^{\circ} \mathrm{C}\right)$, assumes instantaneous ascent, and maximum cooling times for bomb interiors of $10 \mathrm{~min}$. Scenario 2 assumes finite magma ascent times in the conduit (10-30 $\mathrm{min}$ ), corresponding to ascent rates at the high end of the expected range (4-12 m/s), and diffusivity an order of magnitude slower than Scenario 1 $\left(4.7 \times 10^{-11} \mathrm{~m}^{2} / \mathrm{s}\right.$ at $\left.1,030{ }^{\circ} \mathrm{C}\right)$. Scenario 3 assumes the slower diffusion mechanism in olivine $\left(1.8 \times 10^{-12} \mathrm{~m}^{2} / \mathrm{s}\right.$ at $1,030{ }^{\circ} \mathrm{C}$ ), thus requiring longer ascent times $(4-12 \mathrm{~h})$, corresponding to slower ascent rates $(0.15-0.5 \mathrm{~m} / \mathrm{s})$. While we do not advocate one ascent history over the other, if $\mathrm{H}_{2} \mathrm{O}$ re-equilibration does occur during ascent, we believe that the explosive ascent rates consistent with our data $(0.15-12 \mathrm{~m} / \mathrm{s})$ provide a sound confirmation for the accepted range for sub-Plinian eruptions. These different possible ascent and cooling histories for the ash versus bomb MIs can be tested by future work on dynamic eruptive models at Volcán de Fuego, crystal or vesicle distribution studies, and by applying other diffusion clocks $\left(\mathrm{H}_{2} \mathrm{O}\right.$ in clinopyroxene, Wade et al. 2008; or volatiles in melt tubes, Liu et al. 2007; Humphreys et al. 2008). Clearly some combination of ascent/communition $(\sim 10 \mathrm{~min}$ to $10 \mathrm{~h}$ ) and cooling time $(0-10 \mathrm{~min})$ is the most reasonable expectation. Resolution of these different contributions to water loss requires future work to better constrain magma ascent rates and water diffusivities in olivine.

Implications for diffusivity of water in olivine

Multiple experimental studies have investigated the diffusivity of $\mathrm{H}_{2} \mathrm{O}$ and $\mathrm{H}^{+}$in olivine (Mackwell and Kohlstedt 1990; Kohlstedt and Mackwell 1998; Demouchy and Mackwell 2003, 2006). Melt inclusion re-equilibration studies have also been conducted in the laboratory in order to obtain timescales of water loss and water gain through olivine (Hauri 2002; Portnyagin et al. 2008; Chen et al. 2011; Gaetani et al. 2012). Figure 12 compares the results of our field-based experiment with these laboratory-based experiments. Our data are consistent with three scenarios that encompass the upper and lower range of $\mathrm{H}^{+}$diffusivities measured in olivine. Diffusivities of molecular $\mathrm{H}_{2} \mathrm{O}$ have experimentally been shown to be on the order of $10^{-18} \mathrm{~m}^{2} / \mathrm{s}$ (Farver 2010). This is extremely low in comparison with our estimates $\left(10^{-9}\right.$ through $\left.10^{-12} \mathrm{~m}^{2} / \mathrm{s}\right)$ and indicates that the re-equilibration we see is not molecular $\mathrm{H}_{2} \mathrm{O}$ loss (unless $\mathrm{H}_{2} \mathrm{O}$ is escaping along invisible microfractures in the host olivine crystal structure, which we do not suspect). It is more likely that a form of proton diffusion accomplishes the $\mathrm{H}_{2} \mathrm{O}$ re-equilibration, and two mechanisms have been implicated in olivine. The faster one involves proton-polaron (redox) exchange and can occur at lower temperatures $\left(\leq 1,000{ }^{\circ} \mathrm{C}\right)$ and shorter durations $(\sim 1 \mathrm{~h})$ in the laboratory (Mackwell and Kohlstedt 1990; Kohlstedt and Mackwell 1998) and is relevant to our temperature and timescales. The slower mechanism has been shown to operate at higher and lower temperatures and involves proton-metal vacancy exchange (Mackwell and Kohlstedt 1990; Demouchy and Mackwell 2003). Experiments on $\mathrm{H}^{+}$diffusion in iron-free olivine have shown that diffusivities are slower without $\mathrm{Fe}$, and this result is consistent with the diffusivity of metal vacancies being the rate-limiting factor for the $\mathrm{H}_{2} \mathrm{O}$ species in pure forsterite (Demouchey and Mackwell 2003). Recent water-loss and water-gain experiments in melt inclusions are consistent with the slower, vacancy-controlled diffusion (Portnyagin et al. 2008; Chen et al. 2011; Gaetani et al. 2012). Our field-based experiment results in diffusivities consistent with either the faster, redox-controlled diffusive mechanism or the slower, proton-vacancy exchange (Fig. 12) depending on the inferred ascent rate. We discuss here the possibility of each mechanism operating in Fuego olivines.

In comparison with the previous laboratory studies of hydrogen diffusion, Fuego MI re-equilibration occurs at 
comparatively lower temperatures $\left(<1,030{ }^{\circ} \mathrm{C}\right)$ and in olivine with lower Fo values (72-78). The two previous laboratory studies on olivine-hosted MIs (Portnyagin et al. 2008; Chen et al. 2011) were conducted at $1,140{ }^{\circ} \mathrm{C}$ and 1,164-1,288 ${ }^{\circ} \mathrm{C}$ for $48 \mathrm{~h}$ and 1.4-8.2 $\mathrm{h}$, respectively. Both MI studies advocate slower hydrogen diffusion by metal vacancy at these higher temperatures, which would require the slower ascent rates determined in Scenario 3. If ascent rates are higher (Scenario 1 and 2), then the redox mechanism would be necessary, possibly triggered by the lower temperatures in Fuego olivines, consistent with the Mackwell and Kohlstedt's (1990) experimental studies. Compositional effects may also be important in activating the faster redox mechanism, which is ultimately related to the concentration of ferric iron (polarons) in the olivine (Demouchy and Mackwell 2006). Because $\mathrm{Fe}^{3+}$ is generally low (100 ppm) in high-Fo olivine, this mechanism may reach its limit in many of the existing experiments on San Carlos olivine ( Fo90; Mackwell and Kohlstedt 1990; Kohlstedt and Mackwell 1998), synthetic forsterite $\left(\mathrm{Fo}_{100}\right.$; Demouchey and Mackwell 2003), Galapagos olivines (Fo ${ }_{79}-\mathrm{Fo}_{88.5}$; Portnyagin et al. 2008), Vulcano olivines (Fo ${ }_{88-91}$; Chen et al. 2011), Mauna Loa olivines (Fo $\left.{ }_{87-88}\right)$. Our field-based experiment explores new territory by estimating $\mathrm{D}_{\mathrm{o}}$ with olivine ranging from $\mathrm{Fo}_{72-78}$. Tsai and Dieckmann (2002) demonstrated that the concentration of point defects and $\mathrm{Fe}^{3+}$ increase with higher concentrations of $\mathrm{Fe}^{2+}$ in olivine. With higher concentrations of $\mathrm{Fe}^{3+}$ in the Fuego samples, the redox mechanism may stay active for a longer period of time, enabling the $25 \%$ re-equilibration we observe for predicted timescales between 10 and $30 \mathrm{~min}$. The Fe content in olivine has also been shown to affect the solubility of hydrogen (Zhao et al. 2004), which will also affect the rate of re-equilibration through the partition coefficient (Qin et al. 1992). If the Fuego olivines have a higher solubility for hydrogen, we would expect re-equilibration to occur more rapidly. Both of these effects, greater diffusivities and partitioning of $\mathrm{H}$ in low Fo olivines like Fuego's, may enable the fast re-equilibration times and ascent rates of Scenario 1 and 2 .

There is also some debate on the extent of oxidation that a melt inclusion may undergo during dissociation of water and diffusion of $\mathrm{H}^{+}$. If this is limited by the amount of $\mathrm{FeO}$ in the inclusion (which is the major species, along with sulfide, that can be oxidized), then the concentration of $\mathrm{FeO}$ may effectively limit the amount of $\mathrm{H}_{2} \mathrm{O}$ loss. Using Eq. (3) in Danyushevsky et al. 2002, where the maximum extent of $\mathrm{H}_{2} \mathrm{O}$ loss in a $\mathrm{MI}$ is related to $\mathrm{FeO} w t \%$ by a factor of 0.125 , a MI with $8.7 \mathrm{wt} \% \mathrm{FeO}$ could accommodate a maximum of $1.1 \mathrm{wt} \% \mathrm{H}_{2} \mathrm{O}$ loss by redox, which is on the order of what we observe. If the inclusion is below the magnetite liquidus, then magnetite crystals should be observed. Some of the bomb MIs contain dark microlites that could be consistent with magnetite precipitation, but not all that have lost water do (Fig. 134D-2). On the other hand, recent work by Gaetani et al. (2012) on MIs in olivine from Cerro Negro $\left(\mathrm{Fo}_{78-82}\right)$ shows how re-equilibration of oxygen fugacity within a melt inclusion can occur on timescales as rapid as proton diffusion, and so exchange with the surrounding melt is also possible. Further experimental work on the diffusive mechanisms of water, and the effects of oxygen fugacity and olivine composition, is needed to understand the timescales and effects of $\mathrm{H}_{2} \mathrm{O}$ loss from MIs during ascent and cooling of volcanic clasts.

\section{Conclusions}

We have carried out a natural experiment to assess the effect of varying clast cooling rates on the re-equilibration of $\mathrm{H}_{2} \mathrm{O}$ in olivine-hosted melt inclusions, using ash, lapilli, and bomb samples erupted on October 17, 1974, at Volcán de Fuego. All MIs occur in olivines of a restricted range of composition ( $\mathrm{Fo}_{72-78}$ ), have identical trace element ratios, and define major element variations consistent with cotectic crystallization of the observed phenocrysts phases. Moreover, $\mathrm{CO}_{2}$ and $\mathrm{S}$ decrease systematically with increasing $\mathrm{SiO}_{2}$ of the inclusion, consistent with degassingdriven crystallization that relates parental basalt to interstitial andesite liquid. These observations point to a shared magmatic history of the melt inclusions prior to eruption, which involves ascent of a common parental magma and then degassing, crystallization, and entrapment during syneruptive ascent.

The exception to these systematics are the lower water contents and greater extents of post-entrapment crystallization recorded in melt inclusions from the more slowly cooled bomb samples. This $\mathrm{H}_{2} \mathrm{O}$ loss is superimposed on the degassing and crystallization trends and can be identified by consistent offsets to lower $\mathrm{H}_{2} \mathrm{O}$ with respect to $\mathrm{K}_{2} \mathrm{O}$, $\mathrm{S}$, and $\mathrm{CO}_{2}$ in the bomb MIs. When these melt inclusions are restored for this water loss using a calculated $\mathrm{H}_{2} \mathrm{O}-\mathrm{K}_{2} \mathrm{O}$ liquid line of descent, the initial scatter in $\mathrm{H}_{2} \mathrm{O}$ versus $\mathrm{CO}_{2}$ concentrations collapses to an array that is well approximated by simple closed-system degassing. It is thus possible that some significant fraction of previously published melt inclusion data are affected by water loss during posteruptive cooling or during the final stages of ascent, and may not require heroic open-system degassing processes, nor mantle-derived $\mathrm{H}_{2} \mathrm{O}$ variations, as has been invoked. Melt inclusions that derive from scoriaceous bombs and lava flows are particularly suspect. These possibilities are difficult to assess within the published literature, given that most studies do not report the clast size sampled, the MI size, or the distance to the crystal rim. Such length scale 
information may be critical in the interpretation of MI data, and we recommend its reporting in future work. With new techniques coming on line that push the beam-size limits to $<5 \mu \mathrm{m}$ (Raman spectroscopy and nanoSIMS; Mercier et al. 2010; Hauri et al. 2011), issues of diffusive $\mathrm{H}_{2} \mathrm{O}$ loss will become even more important (Chen et al. 2011), especially in small melt inclusions.

The field experiment we have conducted here indicates that 40-100 $\mu \mathrm{m}$ diameter melt inclusions in 400-1,000 $\mu \mathrm{m}$ olivines in pyroclasts larger than $6 \mathrm{~cm}$ in diameter may lose up to $30 \%$ or $\sim 1 \mathrm{wt} \% \mathrm{H}_{2} \mathrm{O}$ and crystallize up to $10 \%$ olivine. The relationships between $\mathrm{H}_{2} \mathrm{O}$ re-equilibration and MI size are consistent with a hydrogen diffusion mechanism. We proposed three scenarios during which re-equilibration could occur. In the first scenario, $\mathrm{H}_{2} \mathrm{O}$ loss occurs post-eruption during cooling of pyroclasts, with diffusivities on the order of the fastest measured in the laboratory. This scenario is inconsistent, however, with two observations: (1) loss of up to $10 \%$ water in some of the smallest melt inclusions $(<50 \mu \mathrm{m}$ diameter) within ash and lapilli, despite insufficient time during post-eruptive cooling even given the fastest known $\mathrm{H}$ diffusivities, and (2) similar $\mathrm{H}_{2} \mathrm{O}$ loss systematics in bomb rims and bomb interiors, despite the fact that they experience different cooling rates. Thus, two other scenarios include re-equilibration prior to eruption, during magma ascent, with varying ascent rates for the ash/lapilli and bomb samples. The different scenarios encompass the extremes in proton diffusion rates, yielding ascent times from 10-30 min to 4-12 h. Although most experimental studies of melt inclusion re-equilibration in the lab have identified the slower vacancy diffusion mechanism as predominant, the lower forsterite content of Fuego olivines and the lower temperatures involved may favor the faster redox mechanism for proton diffusion in olivine.

These results should be an important guide for future MI sampling efforts. Ash and lapilli samples, with clast size $<2 \mathrm{~cm}$ diameter, yield the best-quenched glassy inclusions that reflect equilibrium with their host olivine (i.e., have experienced little to no post-entrapment crystallization) and preserve the highest $\mathrm{H}_{2} \mathrm{O}$ contents. However, even small inclusions $(<50 \mu \mathrm{m}$ diameter $)$ in the samples may suffer some $\mathrm{H} 2 \mathrm{O}$ loss if ascent rates are slow and diffusivities fast. Small bomb samples $(6-7 \mathrm{~cm}$ diameter), like the ones studied here, will contain a range of melt inclusions, spanning from those that have lost substantial $\mathrm{H}_{2} \mathrm{O}$ $(>30 \%)$ in small melt inclusions $(<50 \mu \mathrm{m}$ in diameter) to those that have lost little to none $(>100 \mu \mathrm{m})$. It is possible that with targeted sampling of melt inclusions of different sizes, and different distances to the rim, that the diffusive process of water loss can be harnessed as a useful clock to constrain timescales of magma ascent, fragmentation, and cooling.
Acknowledgments This research was supported by the National Science Foundation grant EAR-09-48533 to ASL and TP and grant EAR-09-48478 to EHH. WR acknowledges NSF support for work on Fuego and nearby volcanoes since 1972, the most recent being PIRE 0530109. We appreciate the technical support of Charles Mandeville and Juliane Gross at the AMNH during the electron probe data collection, Louis Bolge during the LA-ICP-MS data collection, and Jianhua Wang at CIW during SIMS data collection. Constructive reviews from Maxim Portnyagin and Oliver Reubi improved the clarity of our arguments and data presentation. Finally, we want to acknowledge the editorial work of Jon Blundy and the Contributions to Mineralogy and Petrology staff.

\section{References}

Anderson AT Jr (1984) Probable relations between plagioclase zoning and magma dynamics, Fuego Volcano, Guatemala. Am Mineral 69:660-676

Anderson AT Jr, Newman S, Williams SN, Druitt TH, Skirius C, Stolper E (1989) $\mathrm{H}_{2} \mathrm{O}, \mathrm{CO}_{2}, \mathrm{Cl}$ and gas in plinian and ashflow Bishop rhyolites. Geology 17:221-225

Ariskin AA, Barmina GS (1999) An empirical model for the calculation of spinel-melt equilibria in mafic igneous systems at atmospheric pressure: 2. Fe-Ti oxides. Contrib Mineral Petrol 134:251-263

Aubaud C, Hauri EH, Hirschmann MM (2004) Hydrogen partition coefficients between nominally anhydrous minerals and basaltic melts. Geophys Res Lett 31:L20611

Baker DR (2008) The fidelity of melt inclusions as records of melt composition. Contrib Mineral Petrol 156(3):377-395

Baker DR, Freda C, Brooker RA, Scarlato P (2005) Volatile diffusion in silicate melts and its effects on melt inclusions. Ann Geophys 48:699-717

Benjamin ER, Plank T, Wade JA, Kelley KA, Hauri EH, Alvarado GE (2007) High water contents in basaltic magmas from Irazu Volcano, Costa Rica. J Volcanol Geotherm Res 168:68-92

Berlo K, Stix J, Roggensack K, Ghaleb B (2012) A tale of two magmas, Fuego, Guatemala. Bull Volcanol 74:377-390

Blundy JD, Cashman KV (2005) Rapid decompression-driven crystallization recorded by melt inclusions from Mount St Helens volcano. Geology 33(10):793-796

Blundy JD, Cashman KV, Rust AC, Witham F (2010) A case for CO2-rich arc magmas. Earth Planet Sci Lett 290:289-301

Canil D (2002) Vanadium in peridotites, mantle redox and tectonic environments: archean to present. Earth Planet Sci Lett 195:75-90

Carr MJ, Rose WI (1987) CENTAM: a data base of Central American volcanic rocks. J Volcanol Geotherm Res 33:239-240

Carr MJ, Walker JA (1987) Intra-eruption changes in composition of some mafic to intermediate tephras in Central-America. J Volcanol Geotherm Res 33(1-3):147-159

Carr MJ, Feigenson MD, Bennett EA (1990) Incompatible element and isotopic evidence for tectonic control of source mixing and melt extraction along the Central American arc. Contrib Mineral Petrol 105:369-380

Cashman KV (2004) Volatile controls on magma ascent and degassing. AGU Monogr 150:109-124

Cervantes P, Wallace P (2003) The role of water in subduction zone magmatism: new insights from melt inclusions in high-Mg basalts from central Mexico. Geology 31:235-238

Chen Y, Provost A, Schiano P, Cluzel N (2010) Water content in olivine-hosted melt inclusions measured by Raman spectroscopy and possible effect of water re-equilibration during magma ascent and eruption, Eos Trans AGU 91(Fall Meet Suppl) 
Chen Y, Provost A, Schiano P, Cluzel N (2011) The rate of water loss from olivine-hosted melt inclusions. Contrib Mineral Petrol. doi: 10.1007/s00410-011-0616-5

Collins SJ, Pyle DM, Maclennan J (2009) Melt inclusions track preeruption storage and dehydration of magmas at Etna. Geology 37(6):571-574

Costa F, Cohmen R, Chakraborty S (2008) Time scales of magmatic processes from modeling the zoning patterns of crystals. Rev Mineral Geochem 69:545-594

Cottrell E, Spiegelman M, Langmuir CH (2002) Consequences of diffusive reequilibration for the interpretation of melt inclusions. Geochem Geophys Geosyst. doi:10.1029/2001GC000205

Danyushevsky LV (2001) The effect of small amounts of $\mathrm{H}_{2} \mathrm{O}$ on crystallization of mid-ocean ridge and backarc basin magmas. J Volcanol Geotherm Res 110:265-280

Danyushevsky LV, Plechov P (2011) Petrolog3: integrated software for modeling crystallization processes. Geochem Geophys Geosyst. doi:10.1029/2011GC003516

Danyushevsky LV, Della-Pasqua FN, Sokolov S (2000) Re-equilibration of melt inclusions trapped by magnesian olivine phenocrysts from subduction-related magmas: petrological implications. Contrib Mineral Petrol 138:68-83

Danyushevsky LV, McNeill AW, Sobolev AV (2002) Experimental and petrological studies of melt inclusions in phenocrysts from mantle-derived magmas: an overview of techniques, advantages and complications. Chem Geol 183:5-24

Danyushevsky LV, Perfit MR, Eggins SM, Falloon TJ (2003) Crustal origin for coupled 'ultra-depleted' and 'plagioclase' signatures in MORB olivine-hosted melt inclusions: evidence from the Siqueiros Transform Fault, East Pacific Rise. Contrib Mineral Petrol 144:619-637

Danyushevsky LV, Leslie RAJ, Crawford AJ, Durance P (2004) Melt inclusions in primitive olivine phenocrysts: the role of localized reaction processes in the origin of anomalous compositions. J Petrol 45:2531-2553

Demouchy S, Mackwell SJ (2003) Water diffusion in synthetic ironfree forsterite. Phys Chem Miner 30:486-494

Demouchy S, Mackwell SJ (2006) Mechanisms of hydrogen incorporation and diffusion in iron-bearing olivine. Phys Chem Miner 33:347-355

Demouchy S, Jacobsen SD, Gaillard F, Stern CR (2006) Rapid magma ascent recorded by water diffusion profiles in mantle olivine. Geology 34:429-432

Dixon JE, Clague DA, Stolper E (1991) Degassing history of water, sulfur, and carbon in submarine lavas from Kilauea Volcano, Hawaii. J Geol 99:371-394

Dufek J, Manga M, Patel A (2012) Granular disruption during explosive volcanic eruptions. Nat Geosci. doi: 10.1038/NGEO1524

Farver JR (2010) Oxygen and hydrogen diffusion in minerals. Rev Mineral Geochem 72:447-507

Faure F, Schiano P (2005) Experimental investigation of equilibration conditions during forsterite growth and melt inclusion formation. Earth Planet Sci Lett 236:882-898

Frezzotti M-L (2001) Silicate-melt inclusions in magmatic rocks: applications to petrology. Lithos 55:273-279

Gaetani GA, Watson EB (2000) Open-system behavior of olivinehosted melt inclusions. Earth Planet Sci Lett 183:27-41

Gaetani GA, O'Leary JA, Shimizu N, Bucholv CE, Newville M (2012) Rapid re-equilibration of $\mathrm{H}_{2} \mathrm{O}$ and oxygen fugacity in olivine-hosted inclusions. Geology (submitted)

Gonnermann HM, Manga M (2005) Nonequilibrium magma degassing: results from modeling of the ca. 1340 A.D. eruption of Mono Craters, California. Earth Planet Sci Lett 238(1-2):1-16

Grove TL, Parman SW, Bowring SA, Price R, Baker MB (2002) The role of a $\mathrm{H}_{2} \mathrm{O}$-rich fluid component in the generation of primitive basaltic andesites and andesites from the Mt. Shasta region, N. California. Contrib Mineral Petrol 142:375-396

Hauri EH (2002) SIMS investigations of volatiles in volcanic glasses, 2: abundances and isotopes in Hawaiian melt inclusions. Chem Geol 183:115-141

Hauri EH, Weinreich T, Saal AE, Rutherford MC, Van Orman JA (2011) High pre-eruptive water contents preserved in lunar melt inclusions. Science 333:213-215

Heydolph K, Hoernle K, van den Bogaard P, Hauff F (2012) Alongand across-arc geochemical variations in northwestern Central America: increased contribution of enriched mantle to volcanic front and rear-arc lavas from Nicaragua to Guatemala. Earth Planet Sci Lett (submitted)

Hirth G, Kohlstedt DL (1996) Water in the oceanic upper mantle: implications for rheology, melt extraction and the evolution of the lithosphere. Earth Planet Sci Lett 144:93-108

Hon K, Kauahikaua J, Denlinger R, McKay K (1994) Emplacement and inflation of pahoehoe sheet flows: observations and measurements of active lava flows on Kilauea Volcano, Hawaii. Geol Soc Am Bull 106:351-370

Hort M, Gardner J (2000) Constraints on cooling and degassing of pumice during Plinian volcanic eruptions based on model calculations. J Geophys Res 105(B11):25981-26001

Humphreys MCS, Menand T, Blundy JD, Klimm K (2008) Magma ascent rates in explosive eruptions: constraints from $\mathrm{H} 2 \mathrm{O}$ diffusion in melt inclusions. Earth Planet Sci Lett 270(1-2):25-40

Johnson ER, Wallace PJ, Cashman KV, Delgado Granados H, Kent AJR (2008) Magmatic volatile contents and degassing-induced crystallization at Volcan Jorullo, Mexico: implications for melt evolution and the plumbing systems of monogenetic volcanoes. Earth Planet Sci Lett 269(3-4):478-487

Johnson ER, Wallace PJ, Cashman KV, Delgado Granados H (2010) Degassing of volatiles $(\mathrm{H} 2 \mathrm{O}, \mathrm{CO} 2, \mathrm{~S}, \mathrm{Cl})$ during ascent, crystallization, and eruption of basaltic magmas in the central Trans-Mexican Volcanic Belt. J Volcanol Geotherm Res 197:225-238

Jugo PJ, Wilke M, Botcharnikov RE (2010) Sulfur K-edge XANES analysis of natural and synthetic basaltic glasses: implications for $\mathrm{S}$ speciation and $\mathrm{S}$ content as function of oxygen fugacity. Geochim Cosmochim Acta 74:5926-5938

Kelley KA, Cottrell E (2012) The influence of magmatic differentiation on the oxidation state of $\mathrm{Fe}$ in a basaltic arc magma. Earth Planet Sci Lett 329-330:109-121

Kelley KA, Plank T, Ludden J, Staudigel H (2003) Composition of altered oceanic crust at ODP Sites 801 and 1149. Geochem Geophys Geosyst. doi:10.1029/2002GC000435

Kelley KA, Plank T, Newman S, Stolper EM, Grove TL, Parman S, Hauri EH (2010) Mantle melting as a function of water content beneath the Mariana Arc. J Petrol 51:1711-1738

Kent AJR (2008) Melt inclusions in basaltic and related Volcanic Rocks, Mineralogical Society of America. Rev Mineral Geochem 69:273-331

Koga K, Hauri E, Hirschmann M, Bell D (2003) Hydrogen concentration analyses using SIMS and FTIR: comparison and calibration for nominally anhydrous minerals. Geochem Geophys Geosyst. doi:10.1029/2002GC000378

Kohlstedt DL, Mackwell SJ (1998) Diffusion of hydrogen and intrinsic point defects in olivine. Z Phys Chem 207:147-162

Kohut E, Nielsen RL (2004) Melt inclusion formation mechanisms and compositional effects in high-An feldspar and high-Fo olivine in anhydrous mafic silicate liquids. Contrib Mineral Petrol 147:684-704

Kress VC, Carmichael ISE (1991) The compressibility of silicate liquids containing $\mathrm{Fe}_{2} \mathrm{O}_{3}$ and the effect of composition, temperature, oxygen fugacity and pressure on their redox states. Contrib Mineral Petrol 108:82-92 
Liu Y, Anderson AT, Wilson CJN (2007) Melt pockets in phenocrysts and decompression rates of silicic magmas before fragmentation. J Geophys Res. doi:10.1029/2006JB004500

Mackwell SJ, Kohlstedt DL (1990) Diffusion of hydrogen in olivine: implications for water in the mantle. J Geophys Res 95:50795088

Maclennan J, McKenzie D, Hilton F, Gronvöld K, Shimizu N (2003) Geochemical variability in a single flow from northern Iceland. J Geophys Res. doi:10.1029/2000JB000142

Massare D, Metrich N, Clocchiatti R (2002) High-temperature experiments on silicate melt inclusions in olivine at $1 \mathrm{~atm}$ : inference on temperatures of homogenization and $\mathrm{H} 2 \mathrm{O}$ concentrations. Chem Geol 183:87-98

Mercier M, Di Muroc A, Metrich N, Giordano D, Belhadja O, Mandeville CW (2010) Spectroscopic analysis (FTIR, Raman) of water in mafic and intermediate glasses and glass inclusions. Geochim Cosmochimica Acta 74(19):5641-5656

Metrich N, Wallace PJ (2008) Volatile abundances in basaltic magmas and their degassing paths tracked by melt inclusions. Rev Mineral Geochem 69:273-331

Metrich N, Allard P, Spilliaert N, Andronico D, Burton M (2004) 2001 flank eruption of the alkali- and volatile-rich primitive basalt responsible for Mount Etna's evolution in last three decades. Earth Planet Sci Lett 228:1-17

Métrich N, Berry AJ, O'Neill HSC, Susini J (2009) The oxidation state of sulfur in synthetic and natural glasses determined by X-ray absorption spectroscopy. Geochim Cosmochimica Acta 73:2382-2399

Newman S, Lowenstern JB (2002) Volatile-calc: a silicate melt- $\mathrm{H}_{2} \mathrm{O}$ $\mathrm{CO}_{2}$ solution model written in Visual Basic for Excel. Comput Geosci 28:597-604

Parman SW, Grove TL, Kelley KA, Plank T (2011) Along-arc variations in the pre-eruptive $\mathrm{H}_{2} \mathrm{O}$ contents of Mariana arc magmas inferred from fractionation paths. J Petrol 52:257-278

Portnyagin MV, Hoernle K, Plechov PY, Mironov NL, Khubunaya SA (2007) Constraints on mantle melting and composition and nature of slab components in volcanic arcs from volatiles $(\mathrm{H} 2 \mathrm{O}$, $\mathrm{S}, \mathrm{Cl}, \mathrm{F})$ and trace elements in melt inclusions from the Kamchatka Arc. Earth Planet Sci Lett 255:53-69

Portnyagin M, Almeev R, Matveev S, Holtz F (2008) Experimental evidence for rapid water exchange between melt inclusions in olivine and host magma. Earth Planet Sci Lett 272(3-4):541-552

Qin Z, Lu F, Anderson AT (1992) Diffusive re-equilibration of melt and fluid inclusions. Am Mineral 77:565-576

Recktenwald G (2006) Transient, one-dimensional heat conduction in a convectively cooled sphere, updated February 21, 2010, http://web.cecs.pdx.edu/ gerry/epub/

Roedder E (1981) Origin of fluid inclusions and changes that occur after trapping. Fluid inclusions: application to petrology: Mineral Assoc Canada Short Course, Calgary 6:103-137

Roggensack K (2001a) Unraveling the 1974 eruption of Fuego volcano (Guatemala) with small crystals and their young melt inclusions. Geology 29(10):911-914

Roggensack K (2001b) Sizing up crystals and their melt inclusions: a new approach to crystallization studies. Earth Planet Sci Lett 187(1-2):221-237

Rose WI, Anderson AT, Woodruff LG, Bonis SB (1978) October 1974 basaltic tephra from Fuego Volcano-description and history of magma body. J Volcanol Geotherm Res 4(1-2):3-53

Rose WI, Self S, Murrow PJ, Bonadonna C, Durant AJ, Ernst GJ (2008) Nature and significance of small volume fall deposits at composite volcanoes: insights from the October 14, 1974 Fuego eruption, Guatemala. B Volcanol 70:1043-1067
Ruprecht P, Plank T, Lloyd AS (2010) Melt inclusion re-equilibration with complex shapes. Eos Trans AGU 91(Fall Meet Suppl)

Sable JE, Houghton BF, Del Carlo P, Coltelli M (2006) Changing conditions of magma ascent and fragmentation during the Etna 122 BC basaltic Plinian eruption: evidence from clast microtextures. J Volcanol Geotherm Res 158:333-354

Sisson TW, Bronto S (1998) Evidence for pressure-release melting beneath magmatic arcs from basalt at Galunggung, Indonesia. Nature 391:883-886

Sisson TW, Layne GD (1993) $\mathrm{H}_{2} \mathrm{O}$ in basalt and basaltic andesite glass inclusions from 4 subduction related volcanos. Earth Planet Sci Lett 117(3-4):619-635

Spandler C, O'Neill HSC (2010) Diffusion and partition coefficients of minor and trace elements in San Carlos olivine at 1,300 C with some geochemical implications. Contrib Mineral Petrol 159:791-818

Spilliaert N, Allard P, Metrich N, Sobolev AV (2006) Melt inclusion record of the conditions of ascent, degassing, and extrusion of volatile-rich alkali basalt during the powerful 2002 flank eruption of Mount Etna (Italy). J Geophys Res. doi:10.1029/ 2005JB003934

Stroberg TM, Manga M, Dufek J (2010) Heat transfer coefficients of natural volcanic clasts. J Volcanol Geotherm Res 194(4): 214-219

Thomas RME, Sparks RSJ (1992) Cooling of tephra during fallout from eruption columns. B Volcanol 54:542-553

Toplis MJ (2005) The thermodynamics of iron and magnesium partitioning between olivine and liquid: criteria for assessing and predicting equilibrium in natural and experimental systems. Contrib Mineral Petrol 149:22-39

Tsai TL, Dieckmann R (2002) Variation of the oxygen content and point defects in olivines, $\left(\mathrm{Fe}_{\mathrm{x}} \mathrm{Mg}_{1-\mathrm{x}}\right)_{2} \mathrm{SiO}_{4}, 0.2 \leq \mathrm{x} \leq 1.0$. Phys Chem Minerals 29:680-694

Wade JA, Plank T, Melson WG, Soto GJ, Hauri EH (2006) The volatile content of magmas from Arenal volcano. J Volcanol Geotherm Res 157:94-120

Wade JA, Plank T, Hauri EH, Kelley KA, Roggensack K, Zimmer M (2008) Prediction of magmatic water contents via measurement of $\mathrm{H}_{2} \mathrm{O}$ in clinopyroxene phenocrysts. Geology 36:799-802

Wallace PJ (2005) Volatiles in subduction zone magmas: concentrations and fluxes based on melt inclusions and volcanic gas data. J Volcanol Geotherm Res 140:217-240

Wallace PJ, Carmichael ISE (1994) S speciation in submarine basaltic glasses as determined by measurements of SKa X-ray wavelength shifts. Am Mineral 79:161-167

Wallace PJ, Dufek J, Anderson AT, Zhang YX (2003) Cooling rates of Plinian-fall and pyroclastic-flow deposits in the Bishop Tuff: inferences from water speciation in quartz-hosted glass inclusions. B Volcanol 65(2-3):105-123

Witham F (2011) Conduit convection, magma mixing, and melt inclusion trends at persistently degassing volcanoes. Earth Planet Sci Lett 301:345-352

Witham F et al (2011) SolEx: a model for mixed COHSCl-volatile solubilities and exsolved gas compositions in basalt. Comput Geosci. doi:10.1016/j.cageo.2011.09.021

Wright HMN, Cashman KV, Rosi M, Cioni R (2007) Breadcrust bombs as indicators of Vulcanian eruption dynamics at Guagua Pichincha volcano, Ecuador. B Volcanol 69(3):281-300

Zimmer MM, Plank T, Hauri EH, Yogodzinski GM, Stelling P, Larsen J, Singer B, Jicha B, Mandeville CW, Nye CJ (2010) The role of water in generating the calc-alkaline trend: new volatile data for Aleutian magmas and a new tholeiitic index. J Petrol 51:2411-2444 